\title{
El estilo oral y los rostros de Dios en el Apocalipsis
}

\author{
Lourdes García UREÑA \\ Universidad CEU - San Pablo \\ lgarciau@ceu.es
}

Recibido: 19-11-2013

Aceptado: 11-12-2013

\section{RESUMEN}

El Apocalipsis constituye el último libro de la Biblia cristiana. Se trata de un texto escrito para ser leído en voz

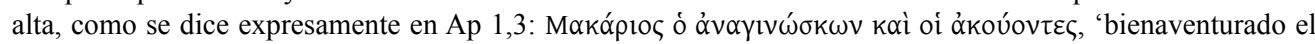
que lee en voz alta y los que escuchan'. Por este motivo, Juan de Patmos configura su obra sirviéndose del estilo oral, el destinado a ser oido, que facilita al oyente/lector la escucha del texto. Entre los distintos recursos de este estilo, las fórmulas y las repeticiones ocupan un lugar destacado en el Apocalipsis, pues facilitan al oyente/ lector el seguimiento de una compleja trama. No obstante, en ocasiones, da la impresión que Juan de Patmos se sirve de las estrategias del lenguaje oral con otras intenciones, concretamente cuando las fórmulas se aplican a

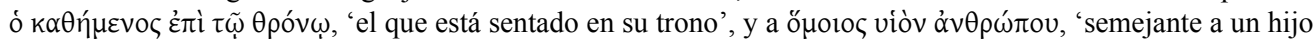
de hombre'. Tras el análisis de los textos, se puede concluir que Juan de Patmos utiliza el estilo oral no solo para que el oyente/lector reconozca e identifique dentro de la trama narrativa a estos personajes, sino también para que a través de su efecto connotativo descubran su rostro, la relación que existe entre ambos y su conexión con la imagen de Dios del AT.

Palabras clave: Nuevo Testamento, Apocalipsis, Septuaginta, estilo oral, fórmulas, repeticiones.

\begin{abstract}
The Book of Revelation is the last book of the Christian Bible. It is a text written to be read aloud, as it is stated

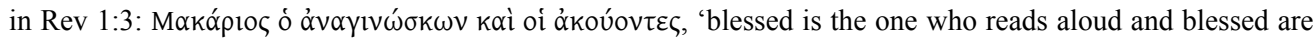
those who hear'. For this reason, John of Patmos shapes his work by making use of the oral style, the style designed to be heard, which facilitates the listening of the text to the listener/reader. Among the different resources of this style, the formulas and repetitions play an important role in the Book of Revelation, because they assist the listener/reader in following of complex plot. Nevertheless, it sometimes seems that John of Patmos makes use of the strategies of the oral style with other intentions, in particular when the formulas are applied to

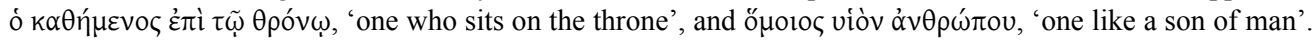
After the analysis of the texts, it is concluded that John of Patmos utilizes the oral style not only so that the listener/reader recognizes and identifies the characters of the plot, but also discovers by means of the connotative effect of the oral style, the face of God, the relationship that exists between these two characters and their connection with the image of God in the OT.
\end{abstract}

Keywords: New Testament, Book of Revelation, Septuagint, oral style, formulas, repetitions. 


\section{INTRODUCCIÓN}

La Biblia cierra sus páginas con uno de sus escritos más sugestivos: el Apocalipsis. Se trata de uno de los libros más fascinantes del corpus bíblico que ha inspirado interpretaciones de la historia, obras de arte en la pintura, en la literatura y también en el cine. En la actualidad presenta un gran atractivo ante la crisis, la magnitud de los desastres naturales y la inseguridad ciudadana. No obstante, la lectura del Apocalipsis resulta ardua y difícil para el lector contemporáneo por varias razones. En primer lugar no conoce con profundidad lo que en el s. I d.C. se designaba con el nombre de Escrituras, que corresponde en gran parte al AT de la Biblia cristiana, por lo que encuentra dificultades para reconocer las continuas alusiones a los textos veterotestamentarios y, como consecuencia, le resulta difícil captar el trasfondo del texto apocalíptico.

Además el lector moderno lee el Apocalipsis como tradicionalmente se hace en la actualidad: en silencio. Sin embargo, en la Antigüedad la lectura se hacía en voz alta, de hecho San Agustín relata con asombro en las Confesiones cómo San Ambrosio leía sin mover los labios ${ }^{1}$. La lectura era un evento social de carácter más o menos público en el que un poeta recitaba versos en las fiestas o banquetes, o bien un lector en el ámbito judeo-cristiano realizaba la lectura del texto sagrado en el seno de la comunidad. Curiosamente, el Apocalipsis hace gala de su lectura pública en voz alta mencionando tanto al lector como a los oyentes ${ }^{2}$ :

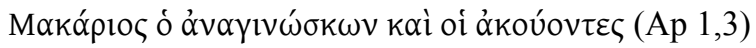

Bienaventurado el que lee en voz alta y los que escuchan.

Esta indicación de la obra implica que el texto del Apocalipsis se escribe para ser leído en voz alta en un contexto concreto: la asamblea cristiana que se reúne para celebrar su fe. Además la lectura en voz alta en cierto modo obligaba a los autores a configurar su obra de una manera concreta con el fin de que la escucha del texto resultase atractiva, pero también fácil de seguir ${ }^{3}$. Se adoptaba lo que se conoce con el nombre de estilo oral, el destinado a ser oído, presente en la literatura bíblica anterior (vetero y neotestamentaria), así como en la literatura greco-romana. Este estilo se caracteriza por el uso del lenguaje formular, las repeticiones, la creación de estructuras aditivas, los elencos de enumeraciones, los comentarios del narrador para interpelar al oyente ${ }^{4}$, etc. De ahí que si el lector moderno no tiene en cuenta la dimensión oral del Apocalipsis, no solo no apreciará la obra, sino que también perderá parte del mensaje que el autor transmite, pues la revelación tiene lugar a través del estilo oral, que incrementa el significado de las

${ }^{1}$ Sed cum legebat, oculi ducebantur per paginas et cor intellectum rimabatur, vox autem et lingua quiescebant. Saepe cum adessemus (non enim vetabatur quisquam ingredi aut ei venientem nuntiari mos erat) sic eum legentem vidimus tacite ( $P L 32,6.3)$.

${ }^{2}$ Un estudio más detenido sobre la lectura en voz alta en el Apocalipsis puede encontrarse en García Ureña (2014: 309-313).

${ }^{3}$ Russo (1992: 21).

${ }^{4}$ Ong (1982, reimpr. 1990: 33-77). 
expresiones al potenciar su efecto connotativo en el lector. Ilustraré lo que acabo de decir mostrando cómo Juan de Patmos presenta el rostro de Dios en el Apocalipsis. Previamente aclararé dos conceptos sobre los que se basa este estudio: la fórmula y la repetición.

Entiendo por fórmula «una unidad semántica (grupo de palabras que transmite un mensaje), recurrente (la expresión ha de aparecer al menos tres veces), que se comunica por medio de una unidad de entonación, cuya longitud y duración depende de la capacidad del auditorio para procesar la información, dos o tres segundos, y cuyo contenido trasciende los elementos denotados remitiendo a un universo semántico más amplio, que llega a ser familiar para el oyente/lector bien porque aparezca en otros textos bíblicos anteriores o bien por su frecuencia en el texto». En cambio, la repetición supone el uso de un único lexema, o de un grupo de lexemas que o carece de un uso recurrente (menos de tres veces), o bien incluye de forma yuxtapuesta más de una unidad de entonación ${ }^{5}$.

\section{EL CONTENIDO DE O OEÕ EN EL APOCALIPSIS: EL DIÁLOGO LITÚRGICO INICIAL}

La obra objeto de estudio se presenta a sí misma como 'A

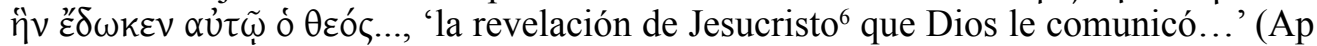

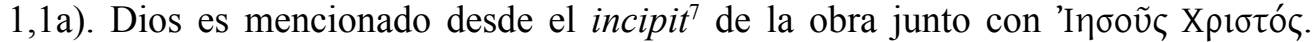
Ahora bien, ó $\theta \varepsilon o ́ s$ es el término habitual en griego para referirse a la divinidad; aparece en poetas, filósofos y ya en ámbito judío: en la Septuaginta, en Filón y en los

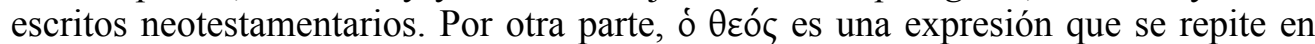
otros momentos de la obra (96 veces), pero los contextos en que aparece no contribuyen a esclarecer cómo es el Dios del Apocalipsis ${ }^{8}$, ya que indican atributos aplicables a cualquier divinidad ${ }^{9}$, se mencionan personajes u objetos que guardan con Él una

\footnotetext{
${ }^{5}$ García Ureña (2014: 313-316).
}

${ }^{6}$ Introduzco el artículo en la traducción española porque su ausencia - como está en el texto griego- puede dar lugar en castellano a una interpretación incorrecta. El autor del Apocalipsis no se refiere a una revelación entre otras posibles, sino a la revelación que él recibe de Jesucristo. En griego el artículo está ausente, porque es un rasgo estilístico del autor. No coloca el artículo cuando menciona un nombre por primera vez, si piensa que no resulta conocido para sus oyentes/lectores.

${ }^{7} \mathrm{Se}$ entiende por incipit la primera frase del texto cuyo función es la de dar a conocer la intención del narrador y funciona como un protocolo de lectura dando información al lector: Marguerat - Bourquin (2001: 129. 175, s.v. incipit).

${ }^{8}$ Se excluyen los contextos donde $\theta \varepsilon o ́ \varsigma$ forma parte de una expresión formular más amplia de origen

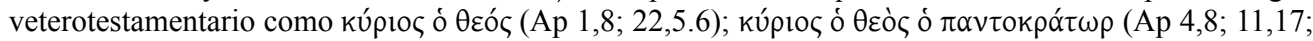
$15,3 ; 16,7 ; 19,6 ; 21,22)$. Se estudiará más adelante por el significado que la fórmula en su conjunto proporciona.

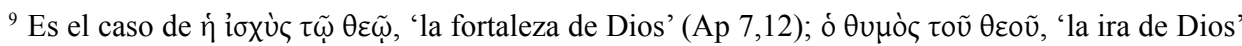

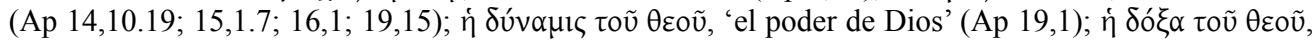
'la gloria de Dios' (Ap 15,8; 21,11.23). 
relación ${ }^{10}$, o es el nombre adoptado para designarle como personaje de la historia ${ }^{11}$. Por tanto, es lógico que el oyente/lector a quien Juan de Patmos dirige su escrito, o el lector contemporáneo se pregunte qué concepto de Dios se esconde tras la expresión ó $\theta \varepsilon o ́ c$, cómo es ese Dios, qué rasgos le caracterizan; si el Dios de la escatología, el Dios de esta nueva revelación se asemeja al Dios del AT o si, por el contrario, refleja ya el nuevo rostro de Dios de los escritos neotestamentarios (Lc 15,11-33; Mt 6,25-30).

Una primera respuesta a estos interrogantes aparece nada más empezar el Apocalipsis en el diálogo litúrgico inicial (Ap 1,4-8), en el que Juan dice:

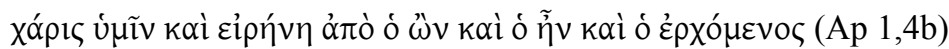

Gracia y paz a vosotros de parte del que está siendo, y del que era, y del que está viniendo.

Estas palabras serán recogidas y ampliadas al final de dicho diálogo, donde tiene lugar una intervención de Dios que irrumpe ex abrupto, tras el oráculo profético ${ }^{12}, \mathrm{y}$ es el mismo Dios quien revela al oyente/lector su identidad:

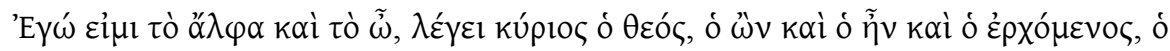

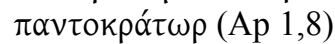

Yo soy el alfa y el omega, dice el Señor Dios, el que está siendo y el que era y el que está viniendo, el todopoderoso.

Cuando el oyente/lector, a quien Juan de Patmos dirigía su obra, escuchaba estas palabras descubría fácilmente quién es el Dios que se revela en el Apocalipsis, pues el discurso divino está constituido por distintas expresiones formulares de raigambre veterotestamentaria que le resultaban familiares y le sugerían una comprensión de Dios que trascendía en cierto modo el significado de la propia expresión.

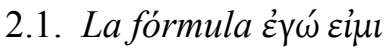

En primer lugar Dios comienza su intervención con un breve sintagma, pero de gran trascendencia: $\dot{\gamma} \gamma \omega \dot{~ \varepsilon i \jmath \mu . ~ S e ~ t r a t a ~ d e ~ u n a ~ f o ́ r m u l a ~ a m p l i a m e n t e ~ d i f u n d i d a ~ e n ~}$ Oriente y debido a su uso generalizado E. Norden le dio el nombre de discurso sote-

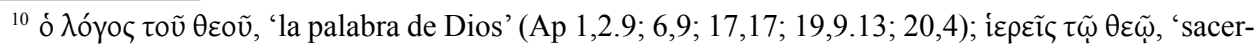

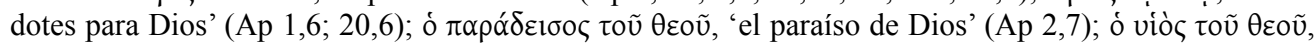

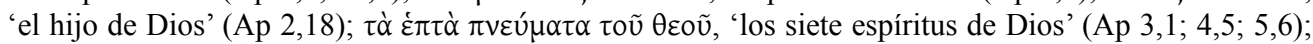

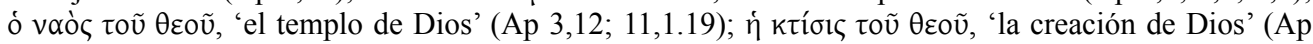

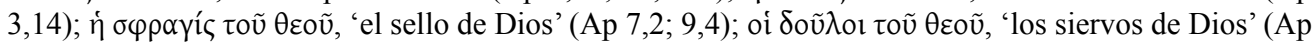

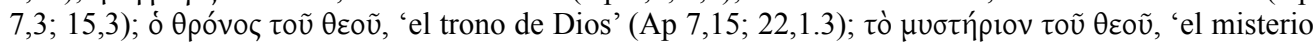

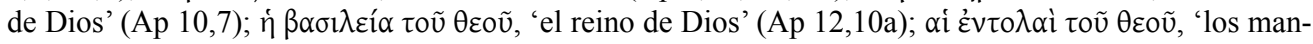

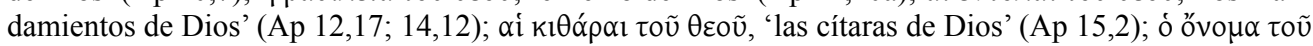

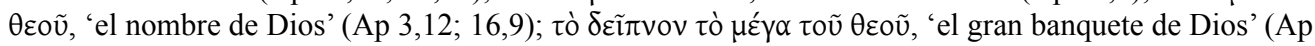
19,17).

${ }^{11}$ Ap 3,$2 ; 5,9.10 ; 7,10.11 .17 ; 8,2.4 ; 9,13 ; 11,11.16 ; 12,5.6 .10 b ; 13,6 ; 14,4.7 ; 16,11.19 .21 ; 17,17$; 18,$20 ; 19,4.5 .10 ; 21,2.3 c .7 .10 ; 22,9.18 .19$.

12 Vanni (1976: 455). 
riológico ${ }^{13}$. En el AT se la conoce como la fórmula de la revelación de Dios porque son las palabras con las que se manifiesta a Moisés en Éx 3,14. No obstante, si se hace un

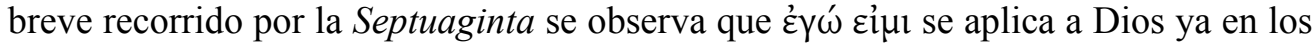
relatos patriarcales en momentos claves en los que Dios se da a conocer al hombre. La primera vez tiene lugar en un episodio relevante para la historia de Israel: la alianza de Dios con Abrán (Gén 17,1); después reaparece cuando se manifiesta a Jacob (Gén $26,24)$, luego cuando le pide que regrese a la tierra prometida (Gén 31,13) y más tarde, cuando ya es anciano, para que se traslade a Egipto (Gén 46,3). No obstante, los

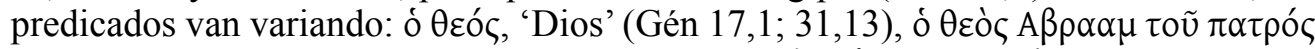

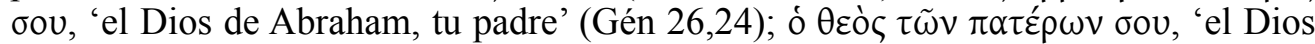
de tus padres' (Gén 46,3).

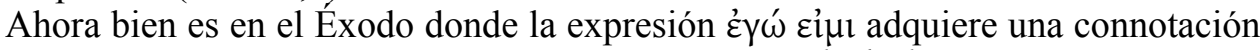

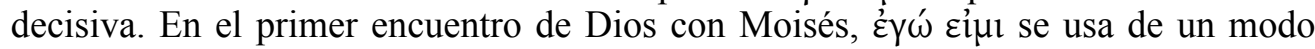
similar al Génesis y sus predicados enlazan con los relatos patriarcales (Gén 17,1; 26,24). De este modo se pone de manifiesto no solo en el contenido, sino también en la forma, que el Dios que se presenta a Moisés es el mismo Dios que se había revelado a los patriarcas:

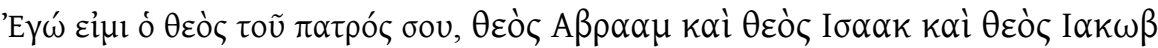
(Éx 3,6)

Yo soy el Dios de tu padre, el Dios de Abraham, el Dios de Isaac y el Dios de Jacob.

Después, ante la pregunta de Moisés sobre cuál es su nombre, Dios afirma $\varepsilon \gamma \omega \dot{~}$

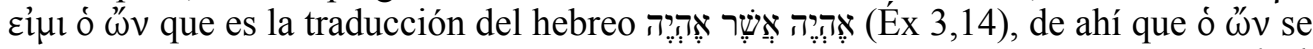
convierte en el nombre de Dios por excelencia, expresándose también a través de $\varepsilon \gamma \hat{\omega}$ Eỉı como ponen de manifiesto los textos de Isaías $(43,25 ; 45,19 ; 51,12)$, que redoblan la expresión formular:

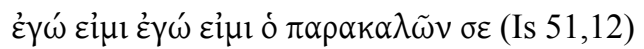

Yo soy Yo soy, el que te consuela.

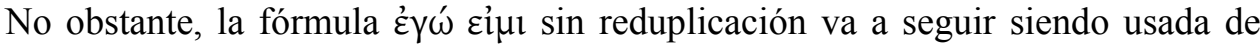
forma constante con diversos predicados a lo largo de los distintos libros bíblicos. Así

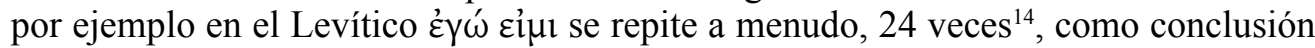
de las leyes para conferir autoridad a lo legislado:

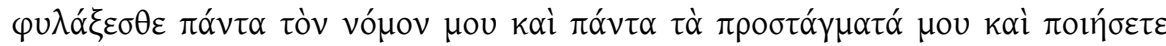

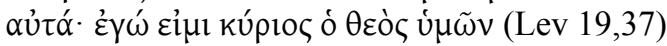

guardaréis todas mis leyes y todas mis prescripciones y las cumpliréis. Yo soy el Señor vuestro Dios.

\footnotetext{
${ }^{13}$ Norden (1956: 191). Schweizer (1939: 64-82) recoge testimonios de la presencia de esta fórmula desde la India hasta Egipto a través de Irán.

${ }^{14}$ Lev 11,44.45; 19,10.12.14.16.18.25.28.30.31.32.34.36.37; 21,23; 22,30; 24,22; 25, 17; 26,1.2.13.44.45.
} 
Su uso llega a ser muy frecuente en los profetas, que retoman la expresión formular

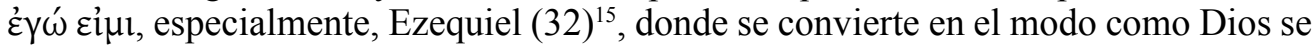
revela a sí mismo a su pueblo y como quiere que le reconozcan:

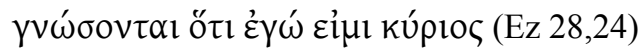

que sepan que Yo soy el Señor.

Tras estudiar la importancia de la fórmula en LXX, se entiende bien que su aparición en labios del propio Dios en el diálogo litúrgico inicial (Ap 1,8a), conmoviera ya desde el principio al oyente/lector puesto que percibía que:

1. El Dios del Apocalipsis elige para su automanifestación la fórmula de la revelación de Dios en la Septuaginta;

2. El contexto en que aparece es similar al de los relatos patriarcales o al del Éxodo. Si en estos se trataba de teofanías, en el caso del Apocalipsis es el primer discurso divino que Dios dirige a oi ơkov́ov $\varepsilon \varepsilon \varsigma$, 'los que escuchan'.

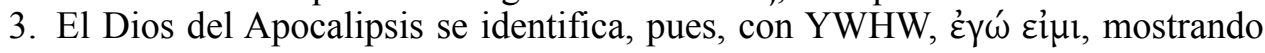
así su esencia y unicidad.

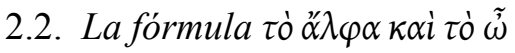

Ahora bien, inmediatamente después el oyente/lector escucha unas palabras que no

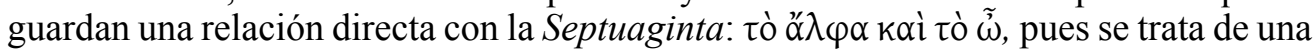
expresión que no aparece ni en ella, ni en la literatura apócrifa anterior, ni tampoco en

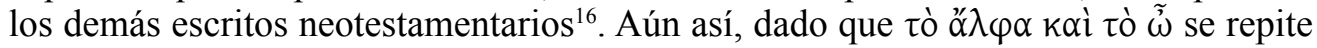
luego en el Apocalipsis dos veces más, Ap 21,6 y 22,13, se puede afirmar que se trata de una expresión formular, probablemente acuñada por Juan de Patmos. Su eco en la literatura cristiana posterior, tanto en los textos de los Padres como en la liturgia ${ }^{17}$, y en el arte ${ }^{18}$, es indiscutible.

${ }^{15} \mathrm{Ez} 7,6 ; 28,22.23 .24 .26 ; 29,6.9 .16 .21 ; 30,8.19 .25 .26 ; 32,15 ; 33,29 ; 34,15.27 .30 ; 35,4.9 .12 .15 ;$ $36,11.23 ; 37,6.13 .28 ; 38,23 ; 39,6.7 .22 .28$.

${ }^{16}$ Aune (1987: 490-491) propone que la fórmula procede de papiros mágicos, donde $A \Omega$ eran las siglas usadas para referirse a un nombre divino constituido por siete vocales, o bien era el principal elemento de IA $\Omega$, nombre divino en el que los judíos podían reconocer el nombre abreviado de YWHW, como aparece en Qumrán (4Q LXX Lev b). Su uso en el Apocalipsis sería un modo de expresar que el Dios que se revela está por encima de cualquier encantamiento.

${ }^{17}$ Clem. Al. Paed. 1.6.36.1.5; Strom. 4.25.157.1; 6.16.141.7; Tert. De monog. 5.3. En la liturgia mozárabe (s. VI) se encuentran antífonas donde "A y ${ }^{\tau} \Omega$ constituyen un título más que se aplica a Cristo ( $P L$ 85,225; 86,177.182). Sirva de ejemplo: «A y $\Omega$, initium et finis, Deus et homo, infinitus initus et praefinitus; in quo et principium Deitatis, et ultimum sentitur humanitas, excedens omnia, vivificans cuncta, et continens universa, miserere nobis quia dignatus es nasci pro nobis dum in te permanes, et nobis appares...» $(P L 86,176)$.

${ }^{18}$ En el arte paleocristiano, sea en la pintura o en la escultura, suelen colocarse las letras alfa y omega junto al crismón. También aparece esta simbología en las tumbas cristianas y en las catacumbas. E, incluso, en el estandarte de victoria de Constantino, denominado el Lábaro de Constantino. Este 


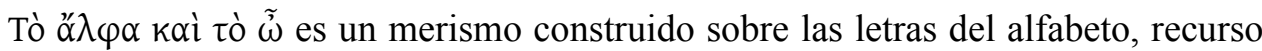
frecuente en la Antigüedad, de hecho, en el mundo judío se acuña la fórmula «del aleph a la tau». Lo propio de esta figura literaria es que incluye todo lo que se encuentra dentro de los dos polos señalados ${ }^{19}$. De ahí que el significado del merismo, al apoyarse en la imagen del alfabeto, la base del lenguaje humano, parece indicar que Dios se presenta como clave hermenéutica para descubrir el sentido de la historia, es decir, se muestra como un Dios que se implica en la historia de los hombres dando razón de su origen, de su desarrollo y de su fin.

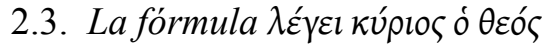

Tras la novedad de la expresión formular, se produce un pequeño inciso con el que se señala que el discurso divino está construido sobre el estilo directo regido:

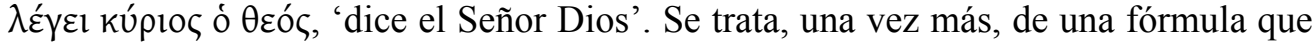
al oyente/lector le resultaba enormemente familiar por ser la empleada en la Septua-

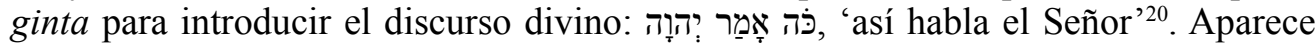
de modo particular en los profetas, quienes la usaban para transmitir fielmente y de forma autorizada el mensaje que Dios les comunicaba. Parece ser que tiene a su vez su origen en la denominada fórmula del mensajero, pues reproduce el modo utilizado en la Antigüedad por los embajadores para transmitir las órdenes, decretos o voluntades de sus monarcas a otro rey: «Así dice mi señor, el rey N. N» ${ }^{21}$.

La Septuaginta dota a la fórmula de formas diversas como son, entre otras: oü $\tau \omega \varsigma$

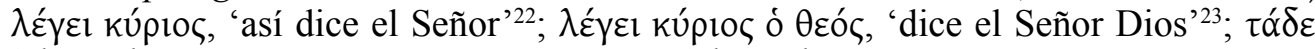

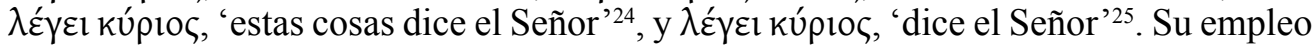
en el Apocalipsis permite al narrador, Juan de Patmos, presentarse como profeta ocul-

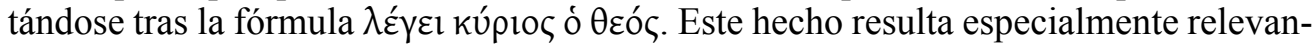

tipo de representación se mantiene durante el periodo del arte románico: De Santiago Fernández (2004: 193-226).

${ }^{19}$ Beale (1999: 199). En el judaísmo era frecuente el juego de palabras con las letras del alfabeto: Kittel (1964, reimpr. 2006: 1-3); Aune (1997: 57); Prigent (2001: 123).

${ }^{20}$ Sirva de ejemplo entre otras: Éx 4,22; 7,17; Is 43,1.14.16; 44,2.6.24; etc.

${ }^{21}$ Sicre (1992: 159, nota 5).

${ }_{22} 1 \mathrm{Cr} 21,10.11 ; 2 \mathrm{Cr} 34,24.26$; Is 8,$11 ; 28,16 ; 30,12.15 ; 37,33 ; 42,5 ; 43,1.14 .16 ; 44,2.24$; $45,1.11 .14 .18 ; 48,17 ; 49,5.7 .8 .22 .25 ; 50,1 ; 51,22 ; 52,4 ; 65,8 ; 66,1 ;$ Jer 14,$10 ; 21,7 ; 23,16 ; 41,4 ; 42,13$.

${ }^{23}$ Am 3,$13 ; 4,3.5 ; 5,27 ; 8,9 ; 9,12.15 ; \mathrm{Jl} 2,12 ; \mathrm{Na} 3,5 ;$ Mal 2,16; Is 41,21; 43,10.12; Jer 2,17.19; 5,18; 16,$1 ; 23,30 ; 26,18.23 ; \mathrm{Ez} 43,19 ; 44,12.15 .27$.

${ }^{24}$ Sirva de ejemplo: Ez 2,$4 ; 3,11.27 ; 4,13 ; 5,5.7 .8 ; 6,3.11 ; 7,2.9 ; 11,5.7 .16 .17 ; 12,10.19 .23 .28$; $13,3.8 .13 .18 .20 ; \quad 14,4.6 .21 ; \quad 15,6 ; \quad 16,3.36 .59 ; \quad 17,3.9 .19 .22 ; \quad 20,3.5 .27 .30 .39 ; \quad 21,3.14 .29 .31 .33$; $22,3.19 .28 ; 23,22.28 .32 .35 .46 ; 24,3.6 .9 .21 ; 25,3.6 .8 .12 .13 .15 .16 ; 26,3.7 .15 .19 ; 27,3 ; 28,2.6 .12 .22 .25$; 29,3.8.13.19.20.

${ }^{25}$ Es el caso de, entre otros: Gén 22,16; Núm 14,28; 2 Re 19,33; 22,19; Sal 11,6; Od 4,9; Os 2,15.18.23; 11,11; Am 1,5.8.15; 2,3.11.16; 3,10.15; 4,6.8.9.10; 7,3.6; 8,3.11; 9,7.13; Mi 4,6; 5,9; Ab 1,4.8; Ha 3,9; So $1,2.3 .10 ; 3,8.19 .20 ; \mathrm{Ag} 1,13 ; 2,14.17$; Za 2,9.14; 10,12; 11,6;12,1; 13,2.8; Mal 1,2; 3,13; Is 1,11.18; 33,$10 ; 48,22 ; 49,1.18 ; 54,17 ; 55,8 ; 58,6 ; 65,7.25 ; 66,2.22 ;$ Jer $1,8.15 .17 ; 2,9.12 .22 .29 ; 3,1.12 .14 .16 .20$; 4,1.9.17; Ez 5,11; 11,8.21; 12,25; 13,6.16; 14,11.14.16.18.20.23; 15,8; 16,8.14.19.23.30.43.48.58.63; 17,$16 ; 18,3.9 .23 .30 .32$ 
te para el concepto de Dios que se desprende de Ap 1,8, pues no es presentado como fruto de la inspiración joánica, sino como la imagen que Dios mismo quiere transmitir

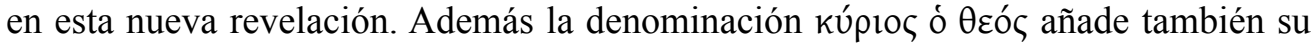
propia connotación, pues кúpıo̧ es el lexema nominal elegido por la Septuaginta para subrayar una imagen específica de Dios: el Dios soberano que es Creador, ejerciendo su dominio sobre el pueblo y el universo, y también Salvador, ya que ha liberado a su pueblo de Egipto ${ }^{26}$.

\subsection{La fórmula ó $\tilde{\omega} v \kappa \alpha i$ ó $\tilde{\eta} v \kappa \alpha i$ ó $\varepsilon \rho \chi o ́ \mu \varepsilon v o \varsigma$}

A continuación, Dios prosigue su discurso y hace suyo un título recién utilizado

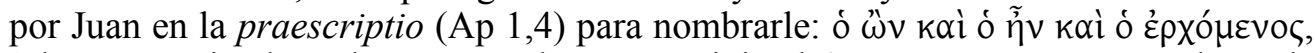
'el que está siendo y el que era y el que está viniendo'. Luego reaparecerá en boca de los cuatro seres vivos (Ap 4,8) y, más tarde, de los ancianos (Ap 11,17), y de un ángel

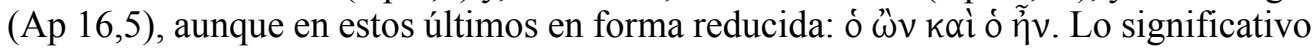
en Ap 1,8 es que Dios reproduce la fórmula exactamente igual a como la acaba de emplear Juan, reforzando así la autoridad del mediador de la revelación.

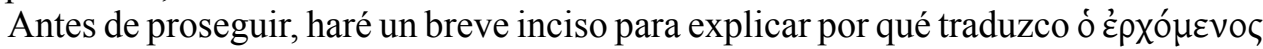
por 'el que está viniendo'. Desde el punto de vista morfológico ó épxó ponde al participio de presente del verbo $\varepsilon^{\prime} \rho \chi 0 \mu \alpha 1$, precedido por el artículo masculino. Los participios en el griego neotestamentario expresan aspecto, más que tiempo, de ahí que sea el contexto el que determine la dimensión temporal del participio ${ }^{27}$. Y es ahí donde surge la dificultad para ofrecer una traducción adecuada. El contexto de la

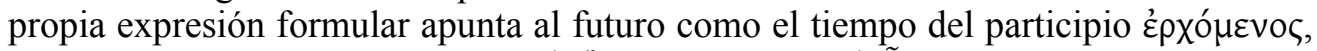
puesto que menciona el presente, ó $̋ v$, y el pasado, ó $\tilde{\eta} v$. De ahí las traducciones españolas: 'que va a venir' ${ }^{\prime 2}$ o 'ha de venir' ${ }^{29}$. No obstante, Ap 1,8 forma parte del diálogo inicial que, dado su carácter litúrgico, se caracteriza por actualizar el mensaje en el momento en que se pronuncian las palabras, como si la acción transcurriese justo ahora, en este momento preciso. Por esta razón, no se puede prescindir del tiempo presente en la expresión formular como reflejan algunas traducciones ${ }^{30}$. Esto viene reforzado por el hecho de que resulta un poco extraño que Juan de Patmos no utilice para

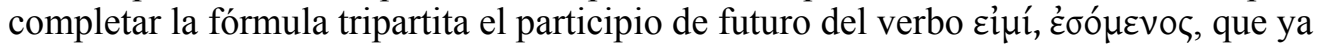
aparece en Lc 22,49 y en Clemente de Alejandría (Strom. 5.6.34.5). Dada la ambivalencia de los contextos que confluyen en Ap 1,8, me inclino por traducir en español: 'está viniendo', sirviéndome de la perífrasis de gerundio que conjuga de algún modo

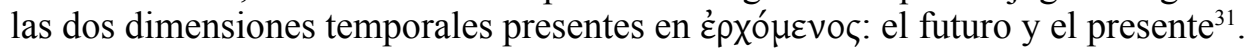

\footnotetext{
${ }^{26}$ Foerster (1965, reimpr. 2006: 1081-1082).

${ }^{27}$ Robertson (1934: 1111).

${ }^{28}$ Sagrada Biblia $\left(1979^{2}\right)$. Traducción que mantiene Manuel Iglesias en su nueva versión del NT: Nuevo Testamento $\left(2003^{2}\right)$.

${ }^{29}$ Nueva Biblia Española (1975).

${ }^{30}$ Sagrada Biblia $\left(1978^{26}\right)$ y Nuevo Testamento Trilingüe (1977, reimpr. 2005): 'que viene'.

${ }^{31}$ La perífrasis de gerundio se caracteriza por tener un aspecto progresivo, de manera que la situación se presenta como ya comenzada, pero no concluida: Real Academia Española (2009: 28.12c).
} 
Volviendo al estudio de la fórmula tripartita, no se sabe con certeza cuál es el origen de esta fórmula. Swete considera que Juan ha conseguido crear una expresión que resultaba muy familiar para el oyente tanto griego como judío ${ }^{32}$. En efecto, la expresión tripartita puede encontrar su fuente de inspiración dentro de un amplio marco helenístico, pues autores como Platón, Pausanias, Plutarco describen a Dios de un modo semejante ${ }^{33}$. Por otra parte, la influencia de la Septuaginta es evidente, tanto

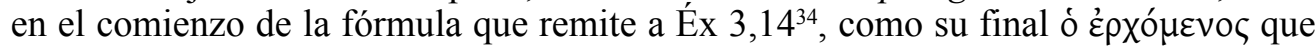
recuerda Is 41,4 , sobre todo, por lo que se refiere a la forma verbal:

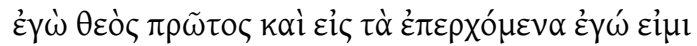

Yo, Dios, soy el primero y para lo que acontecerá Yo soy.

Como sostenía A. Chester, es probable que la fórmula tripartita tenga su origen en un proceso de relectura del texto bíblico donde confluyen Éx 3,14 con los textos de Isaías (Is 41,4; 43,10-15; 44,6; 48,12), llegando a usarse en la liturgia durante el s. I d.C. ${ }^{35}$. De ahí que la expresión formular se haga presente no solo en el Apocalipsis, sino también en otras obras judías como el Targum Pseudo-Jonatán 32,29 ('Ved ahora que yo soy el que soy, el que era y el que he de ser' ${ }^{36}$ ), más tarde en la Mekiltá de Rabbí Simón ben Yohay ('Y él (es) en este mundo, y él (es) en el mundo que vendrá; él (era) en el pasado y será en el futuro que vendrá ${ }^{37}$ ) e incluso en el sentido de una

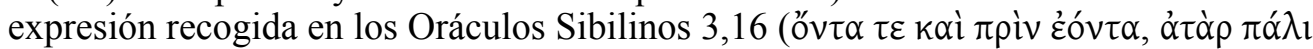

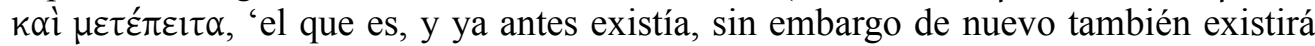
después' $)^{38}$.

Lo que sí es cierto es que la fórmula tripartita pone de relieve la esencia divina, el Yo soy de Éx 3,14, en las tres dimensiones temporales que implica el ser: el presente inmediato, ó $\tilde{\omega} v$; el pasado, ó $\tilde{\eta} v$; y el futuro que comienza a realizarse en el presente a través de la venida, ó épxó $\mu \varepsilon v o c$. Solo estas tres dimensiones del tiempo hacen reali-

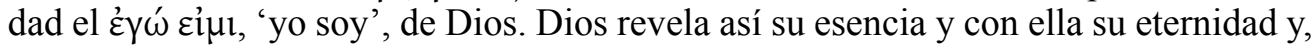
al mismo tiempo, muestra al oyente/lector que el Dios que hace posible la revelación

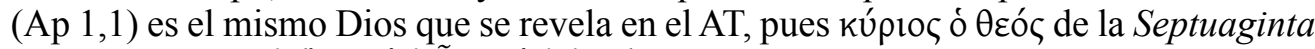

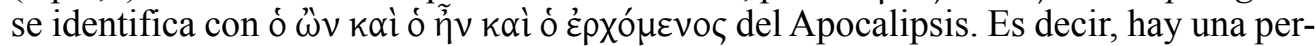
fecta continuidad entre el Dios del Apocalipsis y el Dios de las Escrituras.

${ }^{32}$ Swete (1906, reimpr. 1999: 5).

${ }^{33}$ McNamara (1966: 102). No obstante, McNamara piensa que el origen de la fórmula no es helenístico, sino que está estrechamente ligado al Targum Pseudo-Jonatán (103-117).

${ }^{34}$ Prigent (2001: 115).

${ }^{35}$ Chester (1986: 207-208); Aune (1997: 33) apoya también la existencia de dicha tradición litúrgica y el mismo McNamara (1966: 112) reconoce dicha posibilidad.

${ }^{36}$ Grelot (1987: 49).

${ }^{37}$ Chester (1986: 207, nota 72). Traducción del inglés de la autora. Se trata de una obra posterior al periodo tanaíta: Maier y Schäfer (1996: 270-271, s.v. mekiltá).

${ }^{38}$ Como es sabido, los Oráculos Sibilinos es una obra relevante dentro de la literatura pseudoepigráfica del AT. Recoge una amalgama de textos que abarcan desde s. II a.C. hasta s. v d.C. Los versículos objeto de estudio, a pesar de formar parte del Libro III datado en el s. II a.C., forman parte del comienzo de la obra (1-96) cuya datación es ciertamente posterior, al menos, s. I d.C.: Collins (1992: 3-4). 
Ahora bien, no se puede pasar por alto que Dios pronuncia la fórmula empezando por ó ĥv a diferencia de lo que sucede más adelante en Ap 4,8 donde aparece invertida, reorganizando las dimensiones de tiempo (pasado, presente y futuro): ó

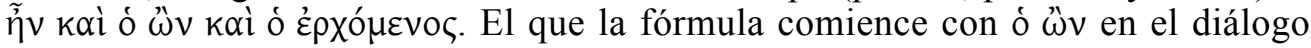
litúrgico inicial resulta particularmente relevante porque consigue recalcar la actualidad del ser de Dios: el Señor es ó âv, 'el que está siendo', ahora, con toda su carga dinámica proveniente de la forma participial, del mismo modo que el ó âv de Éx 3,14. Además, dado el carácter litúrgico del Apocalipsis, ese «ahora» no pertenece a la comunidad joánica del pasado, sino que se refiere al ahora de cada oyente/ lector, de manera que Dios está siendo en el ahora de la comunidad joánica que leía el Apocalipsis, o en el ahora del lector del s. XXI. Es el ahora que se actualiza en la lectura del Apocalipsis: Dios es, está siendo cada vez que se lee hoy y ahora el Apocalipsis.

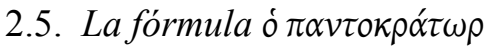

El discurso divino concluye, una vez más, con una fórmula veterotestamentaria: ó $\pi \alpha v \tau o k \rho \alpha ́ \tau \tau \omega \rho$, 'el todopoderoso'. Se trata de la forma reducida de una expresión formular más amplia presente tanto en la Septuaginta ${ }^{39}$ como en el propio Apocalip$\operatorname{sis}^{40}$. No obstante, aparece en Job y en el segundo libro de Macabeos ${ }^{41}$ y en el NT, en 2 Cor 6,18, cuando cita 2 Sam 7,14. Su sentido etimológico, el que gobierna ( $\kappa \rho \alpha ́ \tau \omega \rho)$ todo $(\pi \alpha \vee \tau 0)$, impregna el significado de la expresión formular. Dios se presenta como aquel que tiene el poder, la soberanía sobre la creación en sentido absoluto, como sucedía en los textos veterotestamentarios.

Tras escuchar la intervención de Dios en el diálogo litúrgico inicial, el oyente/lector se ha forjado una idea clara de la imagen de Dios gracias al lenguaje formular y a su poder evocador que permite rememorar el pasado actualizándolo en el presente. Así

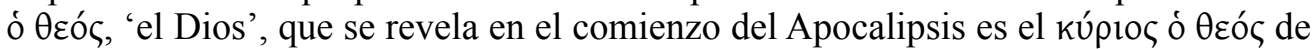

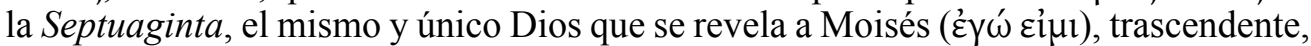

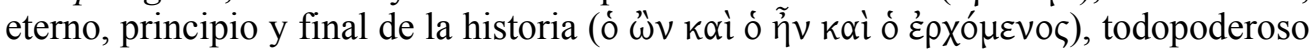
(ó $\pi \alpha \nu \tau o \kappa \rho \alpha ́ \tau \omega \rho)$. Con otras palabras, el Dios que se revela a Juan en el Apocalipsis es el mismo Dios que se revela en el AT, pues no solo recibe el mismo nombre, sino que posee sus mismos atributos y se manifiesta de la misma manera. La única novedad es

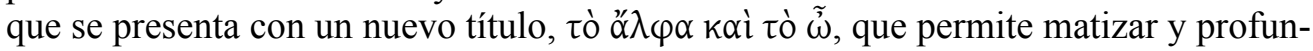
dizar en la imagen ya revelada de Dios.

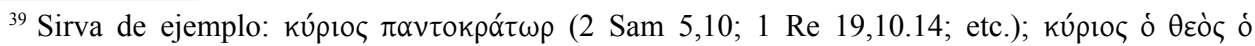

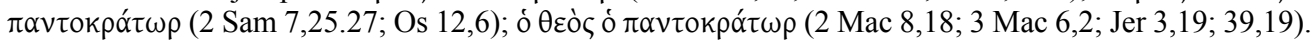

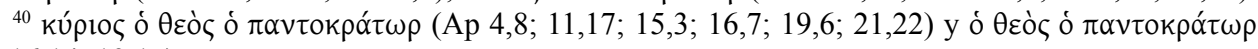
(Ap 16,14; 19,15).

${ }^{41} 1$ Cr 29,12; 2 Mac 1,$25 ; 3,30 ; 5,20 ; 6,26 ; 7,38 ; 8,11.24 ; 15,8.32 ; 3$ Mac 2,2.8; 6,18.28; Job 5,17; $22,17.25 ; 23,16 ; 27,2.11 .13 ; 32,8 ; 33,4 ; 34,10.12 ; 35,13 ; 37,22$; Sab 7,25; Sir 50,14. La expresión ó

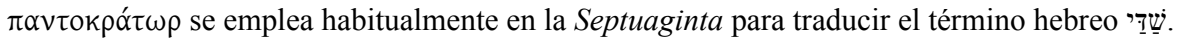




\section{EL ROSTRO DE DIOS EN EL RELATO (AP 1,9-22,16)}

Sin embargo, el oyente/lector era consciente en cierta medida del carácter progresivo de la revelación bíblica, de cómo su contenido se iba comunicando poco a poco en el tiempo y así se iba plasmando en los diversos libros que componen el corpus bíblico. Por esta razón era lógico preguntarse si el concepto de ó $\theta \varepsilon$ có sintetizado en Ap 1,8 como

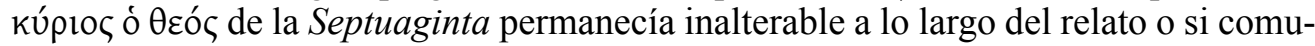
nicaba alguna novedad a lo largo de la revelación efectuada por Jesucristo.

Dos son las intervenciones de Dios en la narración de las visiones y audiciones de Juan: su teofanía y su mensaje final dirigido no a los oyentes/lectores como en Ap 1,4-8, sino a Juan de Patmos. Estos dos momentos son especialmente relevantes para resolver la cuestión.

\subsection{La teofanía}

La teofanía, la manifestación visible de la divinidad de Dios, resulta especialmente esclarecedora. Juan en su papel de narrador prepara cuidadosamente esta visión. Tras concluir el dictado de las cartas a las siete iglesias (Ap 2-3), introduce la fórmula de la

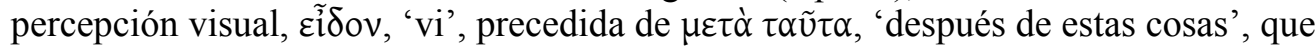
le permite crear la fractura literaria necesaria para iniciar el relato de una visión que no

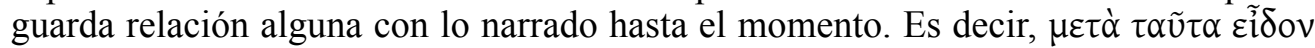
es el recurso que permite al narrador alterar la relación de causalidad-temporalidad propia de cualquier relato.

Inmediatamente después introduce kaì ỉoú, 'y mira', con el que consigue dar énfasis a lo que va a contar a continuación ${ }^{42} \mathrm{y}$, al mismo tiempo, hacer partícipe al oyente/lector de lo que va a ver. Lo primero que Juan y el oyente/lector contemplan es una

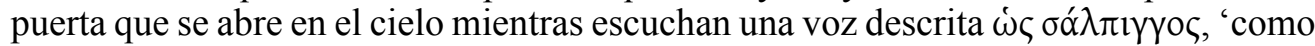
de trompeta' (Ap 4,1). El símil encierra para el oyente/lector del s. I d.C. una connotación especial, le pone en cierto modo en alerta, pues es consciente de que el toque de trompetas en LXX era un evento que, en el contexto cultual, precedía a las teofanías ${ }^{43}$, como bien refleja el relato del Éxodo, cuyo eco resuena en el NT (Heb 12,19):

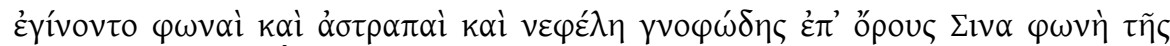

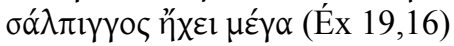

...hubo truenos, relámpagos y una nube densa sobre el monte Sinaí; un sonido de trompeta resonó muy fuerte.

${ }^{42}$ ỉoú es una partícula demostrativa, procedente del griego clásico. LXX la utiliza para traducir la partícula hebrea הִּנה. Su uso es frecuente en los escritos neotestamentarios. Corresponde a la segunda

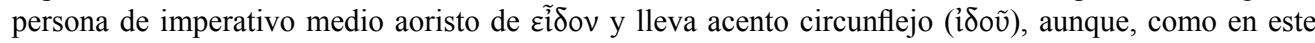
caso, cuando funciona como partícula, tiene acento agudo. Su empleo otorga una gran vivacidad al texto, porque incita al lector a prestar atención a lo que se dice: ‘¡mira!' (BDAG, 3658.1, s.v. íoov; THAYER, 2538, s.v. i̇oú).

${ }^{43}$ Friedrich (1971, reimpr. 2006: 71-88). 


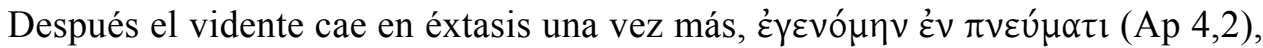
$\mathrm{y}$, para que el oyente/lector no se quede al margen de la historia y de algún modo

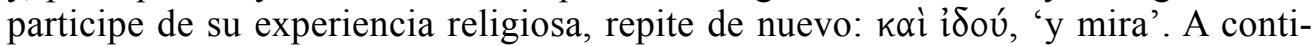
nuación sin pausa alguna empieza a describir o, como diría Cicerón, a poner ante los ojos de sus oyentes ${ }^{44}$ lo que contempla: primero un trono y, sobre él, a alguien

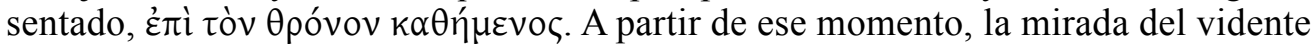
se detiene única y exclusivamente en intentar describir al que está sentado en el trono, cuya identidad permanece oculta. Sin embargo, la descripción no versa ni sobre el vestuario, ni sobre su fisonomía, como había hecho en la visión inaugural (Ap 1,12b-16). Su mirada se focaliza en un único aspecto, el resplandor que despide su persona:

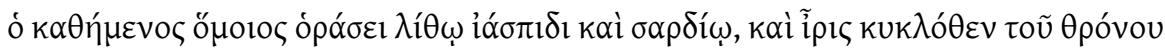

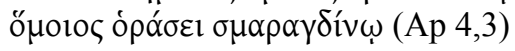

El que está sentado es semejante al jaspe y a la cornalina, y un arco iris ${ }^{45}$ rodea el trono parecido a una esmeralda.

Juan, cegado por el fulgor que desprende el personaje, solo es capaz de describir ese brillo como hacían ya los profetas al contar sus visiones de Dios (Ez 1,26-28; 10,1). Piénsese por ejemplo en Ezequiel, que, al describir su primera teofanía, se limita a mostrar el resplandor que emana de Dios, apoyándose para ello en el campo semántico de las piedras preciosas y en la descripción del arco iris como sucede en Ap 4,3:

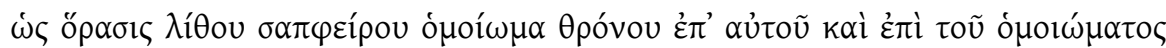

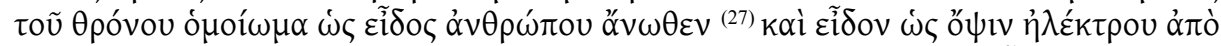

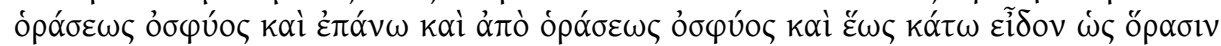

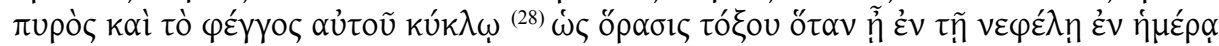

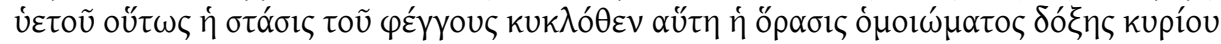
(Ez 1,26-28).

apareció algo como piedra de zafiro en forma de trono sobre él; sobre esa especie de trono, una figura con apariencia humana, en lo alto. ${ }^{(27)} \mathrm{Y}$ vi como un fulgor de ámbar desde lo que parecía su cintura hacia arriba y, desde lo que parecía su cintura hacia abajo, vi como fuego rodeado de fulgor. ${ }^{(28)} \mathrm{Como}$ el arco que aparece en las nubes un día de lluvia, así era el aspecto del fulgor que lo rodeaba. Esta fue la visión semejante a la gloria del Señor.

Y lo mismo sucede en la literatura intertestamentaria (1 Hen 18,8):

\footnotetext{
${ }^{44}$ Cicerón, Inv. 1.55.107.

${ }^{45}$ Me inclino con Beale (1999: 321) por la traducción tradicional de arco iris para el término ĩ prৎ en lugar de halo como propone Juan Mateos $(N B E)$, porque se conserva el eco de la tradición veterotestamentaria (Gén 9,8-17).
} 


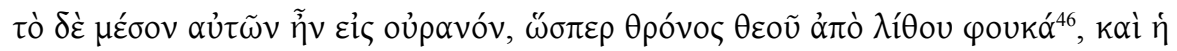

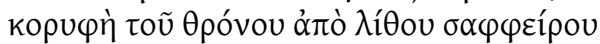

(y el monte) de en medio llega hasta el cielo, como el trono de Dios, de alabastro, y el pináculo del trono de zafiro.

De ahí que la imprecisión de Juan en esta descripción no sea fruto del azar, sino completamente intencionada. El vidente se encuentra ante Dios y, al no poder contemplar directamente su rostro, describe su gloria utilizando una terminología, en cierto modo, ya acuñada anteriormente para contextos semejantes. De este modo tan senci1lo, Juan desvela que quien está sentado en el trono y cuyo resplandor oculta su rostro no es otro que YHWH. Como consecuencia, a partir de ese momento, el nombre ele-

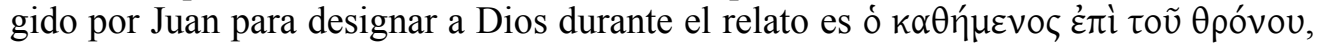
'el que está sentado en el trono', convirtiéndose en una expresión formular (Ap 4,10; $5,1.7 .13 ; 6,16 ; 7,10.15 ; 19,4 ; 21,5)$, heredera una vez más de las Escrituras, concretamente del Salterio ${ }^{47}$. Sirva de ejemplo:

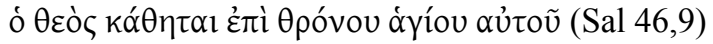 (Sal 47,9) \\ Dios está sentado en su santo trono.}

Por si esta identificación no fuera suficiente, la corte celestial que rodea el trono de Dios en sus cantos de alabanza reafirma la conclusión a la que llega el oyente/ lector, pues se dirigen a Él con las mismas expresiones formulares que Dios acaba

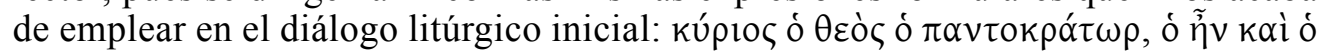

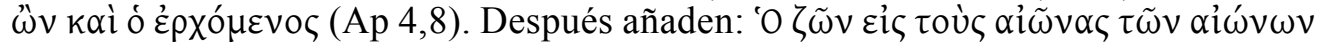
(Ap 4,9.10). Esta última designación, que aparece en forma de discurso indirecto ${ }^{48}$, es una expresión formular presente en LXX (Tb 13,2; Sir 18,1; Dn 12,749) y que reaparece en el Apocalipsis $(10,6 ; 15,7)$. Subraya la eternidad de Dios, pero con un nuevo matiz, la vida que es la analogía que emplea el hombre veterotestamentario para referirse a un Dios que existe, que tiene vida propia a diferencia de los ídolos que, como dice

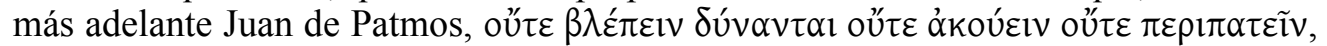
'ni pueden ver, ni escuchar, ni caminar' (Ap 9,20). Por último, hace explícito otro de

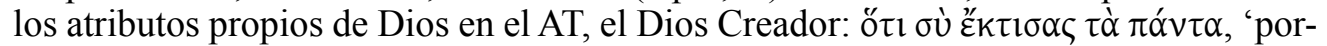
que tú creaste todo' (Ap 4,11).

${ }^{46}$ Refleja una forma aramea que ha adquirido el significado de alabastro: Díez Macho (1984: 55, nota 8$)$.

${ }^{47} \mathrm{El}$ antropomorfismo se mantiene principalmente en la versión hebrea (Sal 2,4; 9,5.8.12; 29,10; $47,9 ; 55,20 ; 80,2 ; 113,5 ; 123,1)$, pues LXX intenta evitarlo, mientras puede. De ahí que la expresión formular se conserve únicamente en Sal 9,5; 46,9; y 79,2: García Ureña $(2013,172)$.

${ }^{48}$ Aune (1997: 307-308) pone de relieve que es el único ejemplo del Apocalipsis en que un himno se reproduce de ese modo.

${ }^{49}$ El libro de Daniel en griego ha sido transmitido en dos versiones diferentes: la de LXX y la de Teodoción: Fernández Marcos (1998: 100-103). En ambas aparece la fórmula aunque varía el caso: acusativo

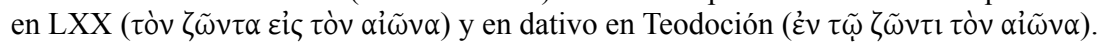


Se puede, pues, concluir que la teofanía del Apocalipsis es típicamente veterotestamentaria, como veterotestamentario es el modo de nombrar a Dios, de describirle y de mostrar otros atributos presentes en el AT. Kúpıos ó Өعós (Ap 1,8) se identifica ple-

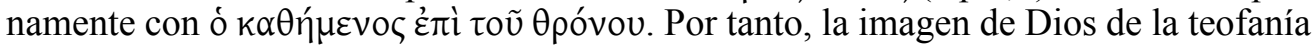
no supone ningún cambio con respecto a la mostrada en el diálogo litúrgico inicial (Ap 1,4.8). El rostro del Dios de la teofanía no es otro que el rostro del Dios del AT y que se mantendrá en el judaísmo.

\subsection{La voz de Dios como clausura (Ap 21,5-6)}

La siguiente intervención directa de Dios tiene lugar prácticamente al final del relato, cuando acontece la visión de la Nueva Jerusalén que desciende del cielo (Ap 21,18). En esta ocasión el oyente/lector escucha las palabras de Dios que comunica a Juan algo sobre sí mismo, precisamente cuando el Apocalipsis está a punto de concluir.

El contexto es el siguiente. Primero Juan contempla una visión extraordinaria que rompe la tensión de la trama: la Nueva Jerusalén ataviada como una novia baja desde el cielo; mientras, se oye una voz que proclama la nueva morada de Dios con los

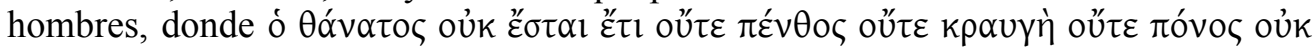

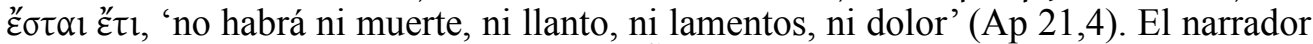

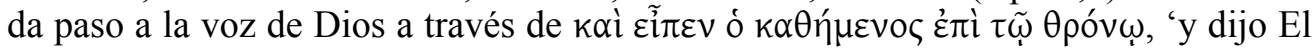
que está sentado en el trono' (Ap 21,5). De este modo tan sencillo queda claro que el Dios de la escatología final no es otro que el Dios de los patriarcas, de los profetas, de los Salmos, pues recibe el mismo nombre. Finalmente se escucha el mensaje divino:

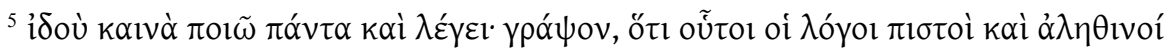

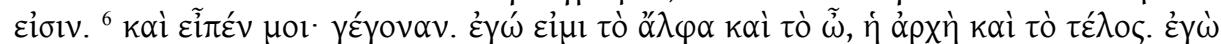

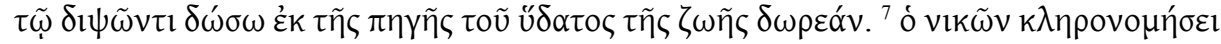

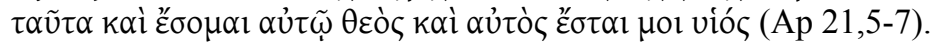

${ }^{5}$ ¡mira! hago nuevas todas las cosas y dijo: «empieza a escribir: estas palabras son fidedignas y veraces». ${ }^{6} \mathrm{Y}$ me dijo: «está hecho. Yo soy el alfa y el omega, el principio y el fin. Yo al sediento le daré gratis de la fuente del agua de la vida. ${ }^{7}$ El que venza heredará estas cosas y yo seré para él Dios, y él será para mí hijo».
}

Su discurso presenta dos partes claramente diferenciadas: lo que Dios hace y lo que Dios dice de sí mismo y de su relación con los hombres.

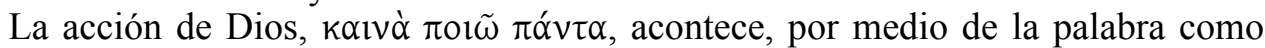
sucedía en el relato sacerdotal (Gén 1-2,4a). Es más, el paralelismo se muestra en el

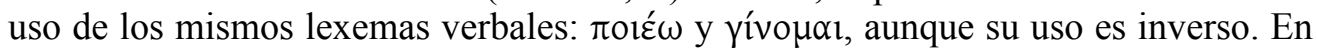

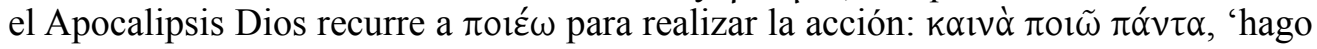
nuevas todas las cosas' (Ap 21,5), mientras LXX suele utilizarlo para la voz del na-

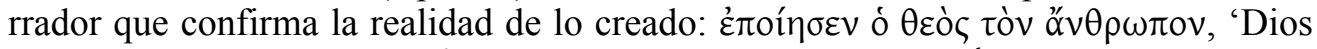
hizo al hombre' (Gén 1,27) ${ }^{50}$. En cambio, el Apocalipsis usa yívoual en su forma de

\footnotetext{
${ }^{50}$ Gén 1,1.7.16.21.25.26.31.
} 
perfecto profético ${ }^{51}$ : $\gamma \varepsilon ́ \gamma o v \alpha v$, 'está hecho' (Ap 21,6), para confirmar que lo dicho es

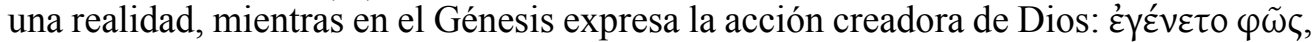
'hágase la luz' (Gén 1,3) ${ }^{52}$. Así pues queda claro que El que sentado en el trono realiza una nueva creación, kaıvò $\pi \alpha ́ v \tau \alpha$, y por si no fuera suficiente, Dios dice a Juan:

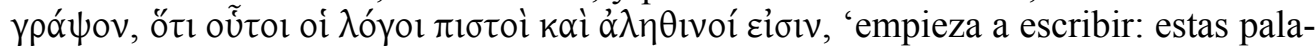
bras son fidedignas y veraces', que confirman y dan veracidad a lo dicho.

Inmediatamente después comienza su autorrevelación que coincide con el comien-

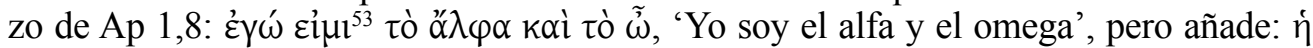

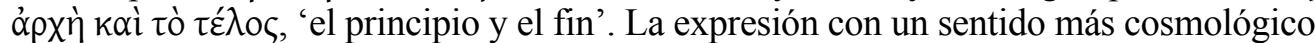
que temporal ya había sido aplicada a la divinidad en textos filosóficos griegos, como muestra D. E. Aune ${ }^{54}$, y también en autores judíos (FJ, Ant. 8.280; Philo, Plant. 93). No obstante, el eco de los textos veterotestamentarios es evidente, teniendo en cuenta ade-

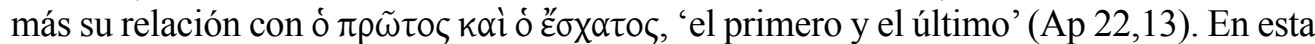
ocasión las expresiones formulares encuentran su origen en el texto hebreo de Isaías:

Is 44,6

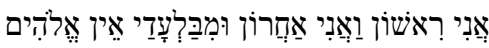
Yo soy el primero y el último y fuera de mí no hay dios.

Is 48,12

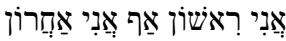

Yo soy el primero y también yo soy el último.

Is 41,4

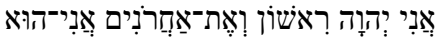
Yo, YWHW, soy el primero y con los últimos yo estaré.

ya que la Septuaginta altera el final de la expresión:

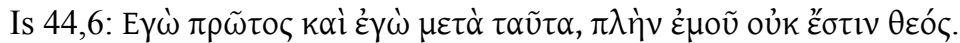

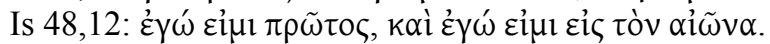

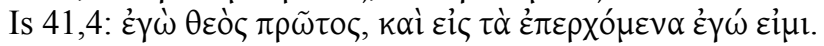

A partir de su resonancia bíblica, el merismo, construido sobre los dos polos del tiempo, apunta en una dirección: el Dios del Apocalipsis es el Dios que inauguró el

${ }^{51} \gamma \varepsilon \dot{\gamma} \gamma \mathrm{ovav}$ es un ejemplo de perfectum propheticum, anuncia un hecho futuro como si hubiera acontecido ya. Es frecuente en la Escritura para referirse a las acciones de Dios, pues permite expresar que dichas acciones se han realizado con independencia del tiempo real o cronológico en el que tengan lugar: Vanni (2005: 294); Belano (2013: 839).

${ }^{52}$ Gén 1,6.14. Aunque también se utiliza en la voz del narrador: Gén 1,3b.6b.9b.11c.

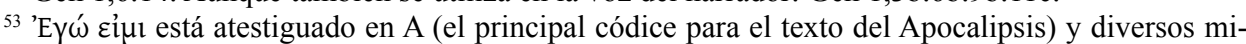
núsculos y versiones. No obstante, falta en el Sinaítico, P, 046 y muchos minúsculos. A pesar de ello,

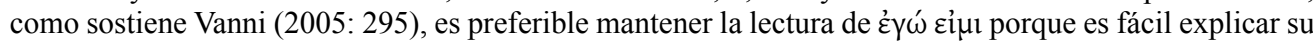
desaparición en los diferentes testimonios, como resultado de la influencia de Ap 22,13 donde se omite la fórmula. En cambio, no ocurre lo mismo con su presencia.

${ }^{54}$ Aune (1998: 1126-1127). 


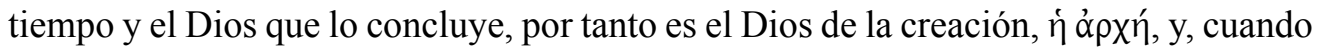

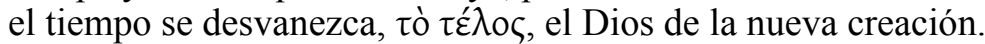

Inmediatamente después explica cuál será el destino de los hombres. Es la primera y última vez en el Apocalipsis en que Dios revela algo referente al destino final: primero anuncia que con la fuente de agua viva saciará la sed de los sedientos (Ap 21,6b). Después da a conocer quiénes recibirán la herencia (Ap 21,7) y quiénes serán excluidos (Ap 21,8). Para hablar de la herencia recurre a la fórmula de la promesa davídica (2 Sam 7,14), aunque en lugar de padre, elige el término Dios como en Ez 37,27,

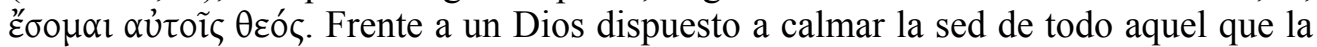
sienta, sin embargo parece reticente en el tema de la herencia: la recibirá únicamente quien venza, solo esos serán hijos, el resto será excluido.

Se puede, pues, concluir que en la autorrevelación final de Dios en el Apocalipsis apenas modifica el concepto de ó $\theta \varepsilon o ́ \varsigma$ que ha mostrado hasta el momento. Las fórmulas elegidas y el modo de narrar la nueva creación muestran ese Dios trascendente, todopoderoso, eterno, principio y fin de la historia, capaz de desplegar su poder creador al final de los tiempos manteniendo la analogía con el relato sacerdotal (Gén 1,1-2,4a). En la última intervención de Dios se pone de relieve la perfecta continuidad que existe entre la imagen de Dios del AT y la que se manifiesta en el Apocalipsis, aunque modifique su relación con los hombres, pues su alianza se realizará ya no con Israel, sino con ò vikũv, 'el que venza'.

\section{EL ESTILO ORAL Y EL OTRO ROSTRO DE DIOS}

A pesar de lo dicho, el oyente/lector del s. I d.C. percibe que a lo largo del relato Juan de Patmos le va mostrando de una forma sutil, pero constante, otro rostro de Dios y lo capta a partir de una serie de anomalías en el uso del lenguaje que le sorprenden por dos motivos. En primer lugar lo propio del estilo oral es el uso de fórmulas específicas para designar a un personaje concreto, de manera que el oyente/lector, al escucharlas, pueda identificar fácilmente al personaje. Sin embargo, el oyente/lector, a medida que escucha el relato, descubre que se aplican a Cristo fórmulas específicas

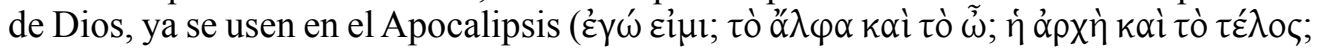

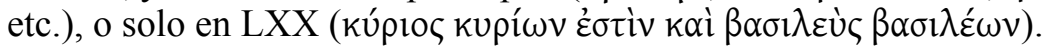

En segundo lugar, este uso del lenguaje formular apunta a un concepto de ó $\theta \varepsilon o ́ s$ que difiere de lo expuesto hasta el momento. Esto explica la perplejidad del oyente/ lector al escuchar el Apocalipsis. Analizaré una a una las distintas expresiones formulares y otros recursos del estilo oral:

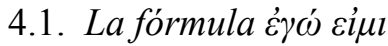

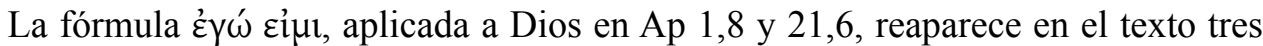
ocasiones $(\mathrm{Ap} 1,17 ; 2,23 ; 22,16)$ más, pero el sujeto de atribución es Jesús ${ }^{55}$. En los

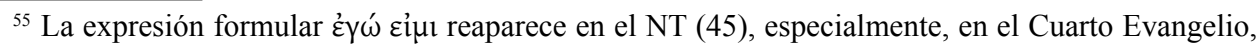
pero, esta vez, en un contexto cristológico: Brown (1966: 533-538); Schnackenburg (1977: 87-102). Je- 
tres casos el contexto es semejante a cuando se aplica a Dios. Se trata de un contexto de revelación, en el que es el propio Jesús quien se da a conocer primero a Juan, pues solo ha sido capaz de ver en Él a alguien őporov viòv óv $\theta \rho \omega ́$ rou, 'como un hijo de hombre' (Ap 1,13); después a la iglesia de Tiatira (Ap 2,18), a quien dirige una de sus cartas; y, por último, de nuevo a Juan al concluir el diálogo litúrgico final (Ap 22,16). El uso de la fórmula en los tres contextos establece un nexo profundo entre kúploৎ ó

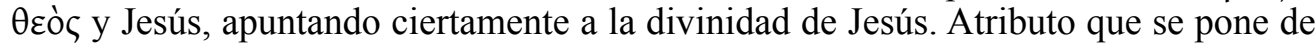
relieve por los predicados empleados.

En el primer caso, Ap 1,17, el predicado presenta una estructura coordinada: ó

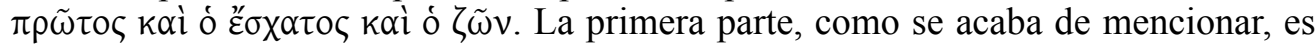
un eco de una expresión formular con la que Dios se revela en Isaías (Is 44,6; 48,12 y 41,4). Por lo que el deseo de Juan de Patmos de subrayar la divinidad de Jesús es indudable, a pesar del modo sutil y velado con que lo hace.

Por lo que se refiere al segundo predicado, ó $\zeta \tilde{\omega} v$, considerado de forma aislada,

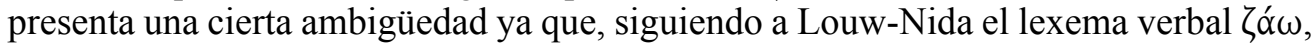
'vivir', tiene tres acepciones: estar vivo, volver a vivir (después de estar muerto) y vivir en sentido de adoptar un comportamiento ${ }^{56}$. $\mathrm{O} \zeta \tilde{\omega} v$ podría referirse tanto a la primera acepción: el que está vivo; como a la segunda acepción: el que ha vuelto a vivir. La Septuaginta no ayuda a resolver la ambigüedad, porque no usa ó $\zeta \tilde{\omega} v$ sin sustantivo que lo acompañe. Sin embargo, es el propio interlocutor, Jesús, quien la resuelve, ya

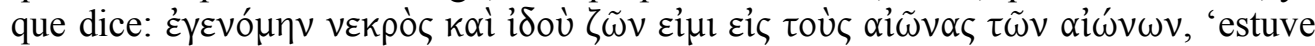
muerto y ¡mira! yo he vuelto a la vida por los siglos de los siglos'. Es decir, explica plenamente el contenido de ó $\zeta \tilde{\omega} v$, yo soy el viviente porque perecí, pero he vuelto a la vida y para ello se apoya en una fórmula que sí aparece en LXX y en el Apocalipsis

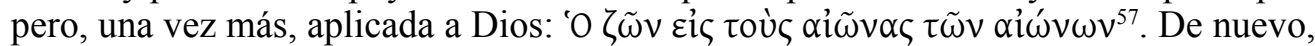
Juan de Patmos subraya la divinidad de Jesús, mientras le aplica un atributo propio de Dios: su inmortalidad (1 Tim 6,16).

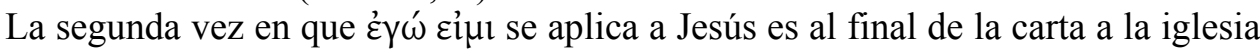
de Tiatira, en la peroratio. Jesús desea dejar claro que ejecutará el castigo a Jezabel y a sus seguidores, por eso afirma:

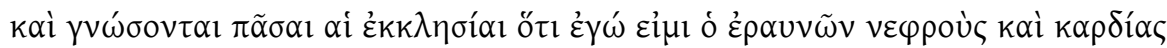
(Ap 2,23)

Así sabrán todas las iglesias que yo soy el que escudriña las entrañas y los corazones.

En esta ocasión, la fórmula no solo alude de nuevo a la divinidad de Jesús, sino que, además, sirve de nexo para aplicarle un atributo específico de Dios: la omniscien-

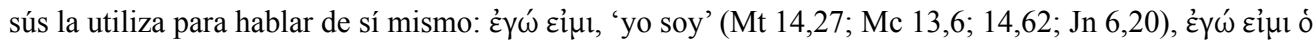

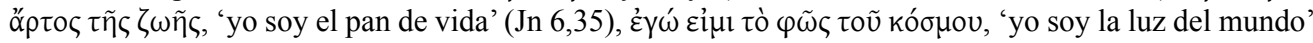
(Jn 8,12). De hecho, solo en dos ocasiones se usa la fórmula para referirse a Dios y, en ese caso, es para citar pasajes del AT (Mt 22,32 reproduce Éx 3,6; 1 Pet 1,16; Lev 19,2).

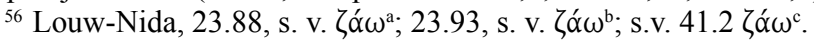

${ }^{57}$ Vid. supra, 181. 
cia, que le permite penetrar en lo más íntimo de la persona ${ }^{58}$. De hecho, el texto del Apocalipsis remite a Jer 17,10a:

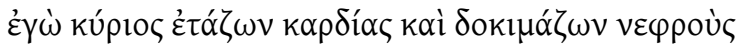

Yo, el Señor, soy el que escudriña los corazones y examina las entrañas.

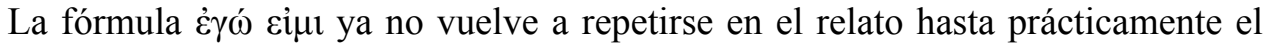
epílogo final (Ap 22,16) ${ }^{59}$, en el momento en que Jesús se dirige a Juan y le dice:

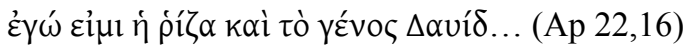

yo soy la raíz y la estirpe de David...

De este modo, Juan consigue reafirmar la naturaleza divina de Jesús al tiempo que muestra una de las prerrogativas propias del Mesías: ser descendiente de la casa de David. El Mesías, pues, no es solo hijo de Dios como si se le hubiera otorgado un título, sino que es Dios porque su esencia es divina: $\varepsilon \gamma \omega \dot{~ \varepsilon i \jmath \mu t . ~}$

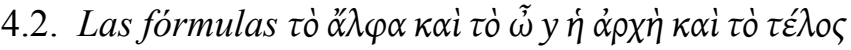

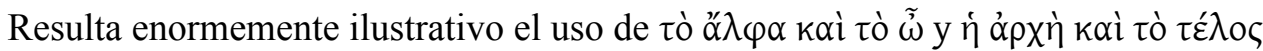
en el Apocalipsis. La obra abría sus páginas con la revelación de Dios como tò ớ $\lambda \varphi \alpha$ kaì tò $\tilde{\omega}(\mathrm{Ap} 1,8)$ y con estas mismas palabras la concluía durante la nueva creación:

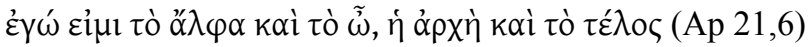

Yo soy el alfa y el omega, el principio y el fin.

Ahora, en el epílogo final, en plena autenticación de la obra, Jesús se revela a Juan de un modo absolutamente novedoso, calcando prácticamente las últimas palabras de Dios:

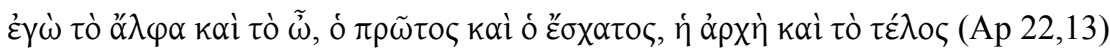

Yo soy el alfa y el omega, el primero y el último, el principio y el fin.

$\mathrm{Su}$ discurso comienza con el lexema pronominal de primera persona de singular, $\dot{\varepsilon} \gamma \dot{\omega}$, enfatizando así su presencia. Inmediatamente después hace suya la fórmula con

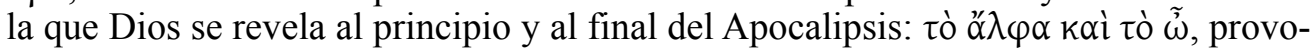
cando un cierto impacto sobre el oyente/lector, pues es una expresión formular especí-

${ }^{58}$ Como señala Aune (1998: 206), son numerosos los pasajes tanto del AT como de la tradición judeo-cristiana, donde se pone de manifiesto que Dios es el único capaz de conocer lo que hay en el corazón de los hombres: 1 Sam 16,7; 2 Sam 14,20; 1 Re 8,39; 1 Cr 28,9; 2 Cr 6,30; Sal 44,21; 139,1-6.23; Sab 7,1; Sir 1,30; 15,18; 42,18-19; etc.

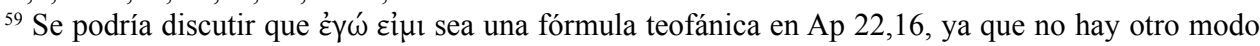
de decirlo. Sin embargo, su función es similar a la que desempeña en el Cuarto Evangelio cuando Jesús declara que él es el pan de vida (Jn 6,35.48), la luz del mundo (Jn 8,12), la puerta de las ovejas (Jn 10,7).

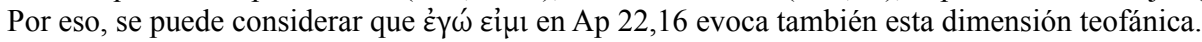


fica de Dios que apuntaba a que solo en Él se encuentra la gramática para entender el acontecer de la historia y ahora es el mismo Jesús quien se la apropia en coherencia,

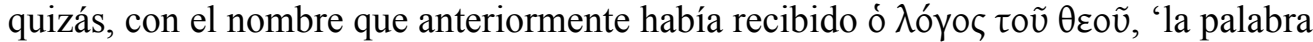
de Dios' (Ap 19,13). A continuación Jesús introduce un título propio con el que se

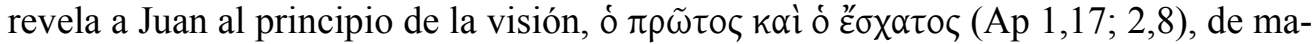
nera que el oyente/lector no duda en quién es el personaje. Finalmente concluye con el

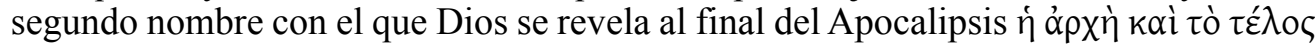
(Ap 21,6). La divinidad de Jesús queda así, una vez más, puesta en evidencia. Jesús es Dios y esta idea queda especialmente puesta de relieve en un momento crucial de la obra, el epílogo, cuya función es ofrecer las claves de la misma.

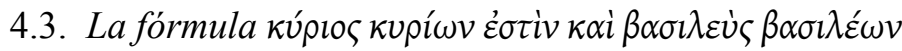

Es una fórmula que aparece por primera vez en la Septuaginta en el libro de Daniel, en un momento de especial revelación, la confesión del rey Nabucodonosor en la que reconoce al Dios de Israel como el único y verdadero Dios ${ }^{60}$ : 4,37).

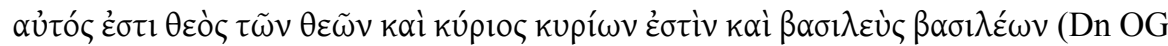

él es Dios de dioses y Señor de señores y Rey de reyes.

También la fórmula se reproduce en cierta medida en la literatura extrabíblica, en el libro 1 de Henoc; esta vez, en boca de los arcángeles Miguel, Uriel, Rafael y Gabriel, que se dirigen a Dios para pedirle justicia:

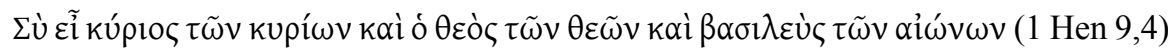
Tú eres Señor de señores, Dios de dioses, Rey de eras.

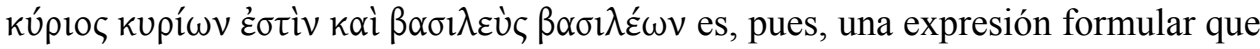
se aplicaba a Dios para subrayar su unicidad y su soberanía absoluta sobre el mundo.

En el Apocalipsis aparece en dos momentos de especial relevancia: cuando el ángel anuncia a Juan la victoria del Cordero sobre la bestia esgrimiendo como argumento precisamente que el Cordero es kúpı $17,14)$ y cuando, al describir al Jinete, afirma que ese es el nombre que lleva en el manto y en el muslo (Ap 19,16). De este modo, a través de estas fórmulas, Juan pone de manifiesto no solo que el Cordero y el Jinete es el mismo Jesús que se presenta con distintas apariencias, sino también que Jesús es Dios, pues está usando la misma expresión que Nabucodonosor, lo cual provocaría cierta conmoción en el oyente/lector, dada la solemnidad inherente al origen de la propia expresión formular.

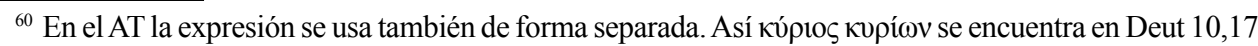
y Sal 135,3 (también se usaba entre los reyes del Antiguo Oriente: Aune [1998: 954]); $\beta \alpha \sigma \iota \lambda \varepsilon \dot{\varsigma} \varsigma \beta \alpha \sigma \imath \lambda \varepsilon ́ \omega v$, aunque con artículo, $\beta \alpha \sigma \imath \lambda \varepsilon \dot{\varsigma} \varsigma \tau \tilde{\omega} v \beta \alpha \sigma \imath \lambda \varepsilon ́ \omega v$, en 2 Mac 13,4; 3 Mac 5,35. En el NT se encuentra un ejemplo de la doble expresión en 1 Tim 6,15 aplicada también a Dios, aunque sustituyendo el sustantivo que constitu-

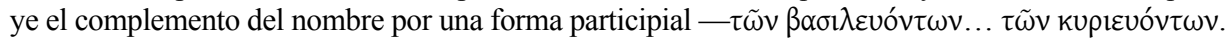




\subsection{La fórmula $\dot{\omega} \varsigma \varphi \omega v \dot{\eta} \dot{v} \delta \alpha ́ \tau \omega \nu \pi \circ \lambda \lambda \hat{\omega} v$}

El uso de este símil para describir la voz de Jesús en la visión inaugural resulta particularmente revelador para el oyente/lector del s. I d.C.:

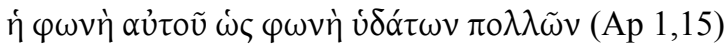

su voz era como el estruendo de aguas caudalosas.

Se trata de una expresión formular que si bien solo se usa en LXX en una ocasión para describir el ruido de las alas de los querubines de la visión de Ezequiel $($ Ez 1,24) - quizás por su tendencia a eliminar los antropomorfismos y antropopatismos ${ }^{61}$ - en la versión hebrea se emplea en tres ocasiones para describir no tanto los querubines, como la voz de Dios (Ez 1,24; 43,2; Sal 93,4). Es más, el texto hebreo matiza el símil afirmando que el ruido es semejante a la voz de Dios:

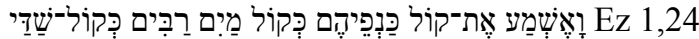
escuché el ruido de sus alas, como el estruendo de aguas caudalosas, como la voz de Sadday.

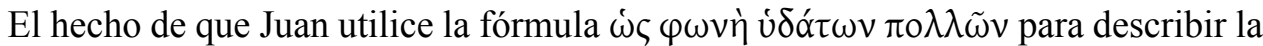
voz de Jesús es un modo sutil de mostrar la divinidad de Jesús ya desde el comienzo del relato ${ }^{62}$.

\subsection{Las repeticiones}

Ahora bien, el intento de Juan de mostrar que Jesús es Dios no acaba en el lenguaje formular, sino que también se apoya en repeticiones que se difuminan a lo largo del relato dando lugar a una música de fondo permanente en la que se insiste en la divinidad de Jesús.

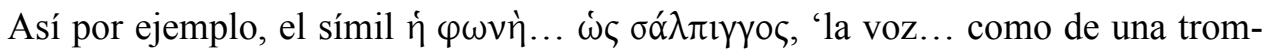
peta', se utiliza tanto para introducir la visión inaugural de Jesús $($ Ap 1,10), como la teofanía del que está sentado en el trono (Ap 4,1). El uso repetido de la expresión es un modo de equiparar las dos visiones en cuanto a la solemnidad y también de mostrar indirectamente la divinidad de Cristo, pues el preludio de su visión acontece del mismo modo que la teofanía del Apocalipsis y de las narradas en la Septuaginta. Por otra parte, como ya mencioné, lo propio de las teofanías es describir el esplendor y fulgor que Dios emite y en este mismo aspecto insiste Juan al describir a Jesús (Ap 1,12-16). De hecho, aunque enumera los rasgos que sobresalen de su fisonomía (cabeza, cabellos, ojos, etc.), los describe mediante atributos y símiles que ponen de relieve el resplan-

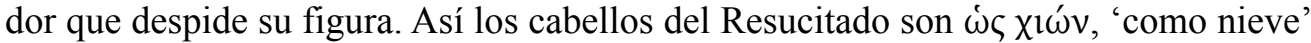

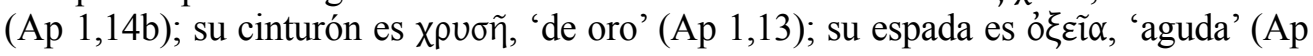

${ }^{61}$ Trebolle (1993: 463).

${ }^{62}$ Esta fórmula se utiliza también para describir la voz del cielo $($ Ap 14,2) y de la multitud innumerable (Ap 19,6). Es un ejemplo de las denominadas fórmulas de identidad, cuya finalidad es mostrar que los personajes pertenecen al mismo contexto, en este caso, el celestial: García Ureña (2013: 161). 


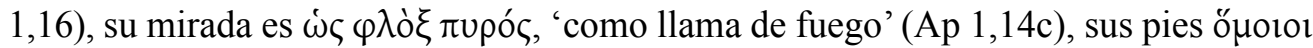

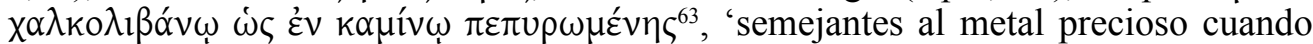

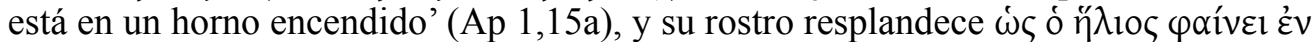

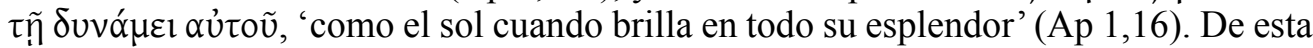
manera, Juan establece cierta semejanza entre la descripción de Cristo Resucitado y la de Dios. Lo mismo ocurre cuando describe a Jesús sentado sobre una nube (Ap 14,14)

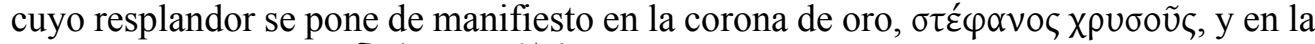

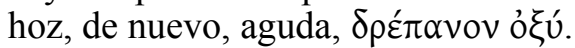

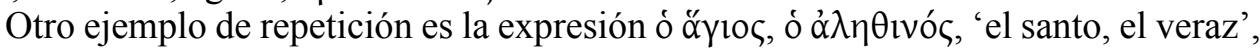
formada a partir de dos atributos específicos de Dios en la Septuaginta. El primero,

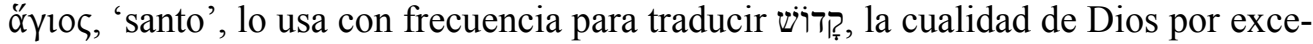
lencia ya que expresa con un solo vocablo su naturaleza ${ }^{64}$. Así en el Levítico, Dios

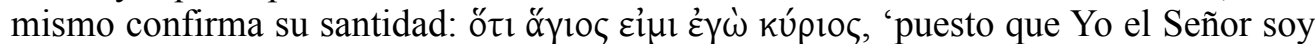
santo' (Lev 11,$45 ; 19,2 ; 20,26)$, y en los profetas, se convierte en uno de sus principa-

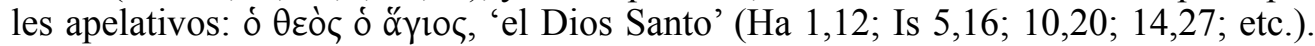
Algo similar sucede con $\alpha \lambda \lambda \theta$ ivó, , 'veraz'. En la Septuaginta designa tanto a Dios:

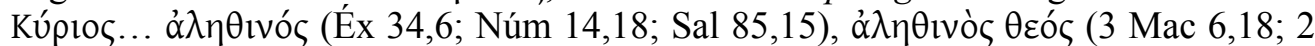

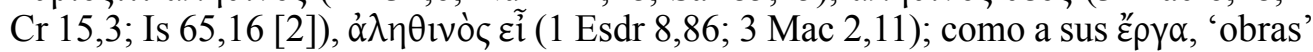

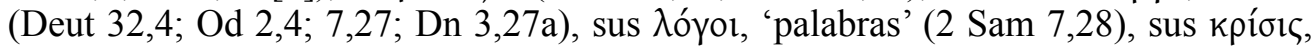
'juicios' (Tb 3,2.5; Sal 18,10; Od 7,31; Dn 3,27b.31), y sus ßouגń, 'designios' (Is 25,1). LXX no hace más que traducir los lexemas hebreos: אֶֶֶ, 'verdad', 'veracidad', y fican $^{65}$, o, con palabras de Weiser, la verdad es lo que hace que Dios sea Dios ${ }^{66}$.

En el Apocalipsis la primera vez que se emplea es en la superscriptio de la carta a la iglesia de Filadelfia (Ap 3,7) en la que Jesús se está presentando a la comunidad. Un poco más tarde, aparecerá en el discurso de las almas inmoladas con el que alaban a Dios (Ap 6,10). Por lo que, una vez más, Jesús se presenta con atributos específicos de Dios en los textos veterotestamentarios.

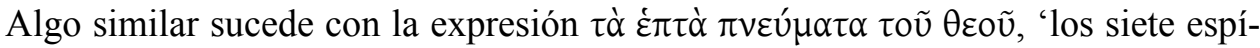
ritus de Dios'. Aparece 4 veces al inicio del Apocalipsis. Unas veces aplicada a Dios (Ap 1,4; 4,5) y otras a Jesús (Ap 3,1; 5,6). Así Juan de Patmos muestra que Jesús posee una de las prerrogativas propias de Dios.

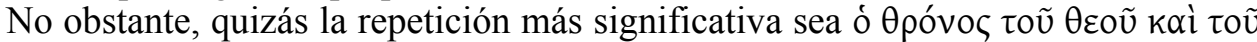
ápvíov, 'el trono de Dios y del Cordero'. Aparece diseminada lo largo de la obra. Consta de una estructura bimembre en la que se menciona juntamente a Dios y al Cordero. En el primer miembro aparece Dios, mostrando así su primacía, y en el segundo,

${ }^{63}$ La forma $\pi \varepsilon \pi \cup \rho \omega \mu \varepsilon ́ v \eta \varsigma$ constituye una anomalía gramatical. No obstante, es la forma atestiguada en el Codex Alexandrinus y en el Ephraemi Parisiensis. En cambio, en el Codex Sinaiticus, así como la traducción que ofrece la Vulgata e Ireneo, se encuentra $\pi \varepsilon \pi \nu \rho \omega \mu \varepsilon ́ v \omega$, que iría de acuerdo con

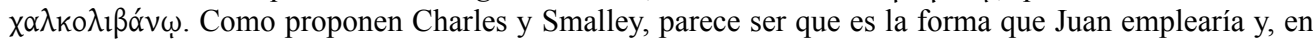

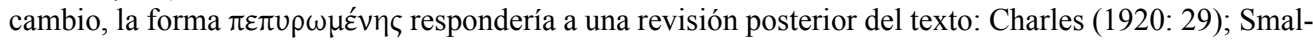
ley (2005: 45).

${ }^{64}$ Procksch (1964, reimpr. 2006: 100).

${ }^{65}$ Quell (1964, reimpr. 2006: 236).

${ }^{66}$ Weiser (1968, reimpr. 2006:185). 
el Cordero. El modo de designar a Dios varía a lo largo del relato. Unas veces aparece la expresión formular de raigambre veterotestamentaria: ó $\kappa \alpha \theta \eta ́ n \varepsilon v o \varsigma ~ \varepsilon ̇ \pi i ~ \tau \tilde{\omega} \theta \rho o ́ v \omega$ (Ap 5,13; 6,16; 7,10); y otras veces se sirve de la metonimia: ó Өpóvo (Ap 7,9; 21,1, 22,3). Por lo que se refiere al Cordero, siempre es mencionado con el lexema nominal ápvíov y va precedido por la conjunción kaí (Ap 5,13; 6,16; 7,9.10; 22,1.3). Las repeticiones son las siguientes:

\begin{tabular}{|c|c|}
\hline \multicolumn{2}{|l|}{ REPETICIONES } \\
\hline 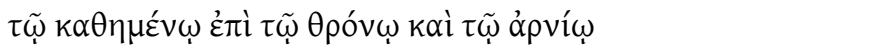 & Ap 5,13 \\
\hline 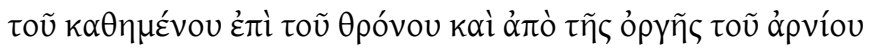 & Ap 6,16 \\
\hline 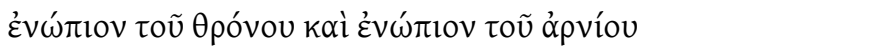 & Ap 7,9 \\
\hline 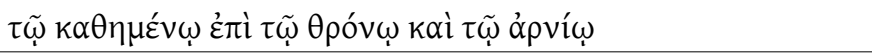 & Ap 7,10 \\
\hline 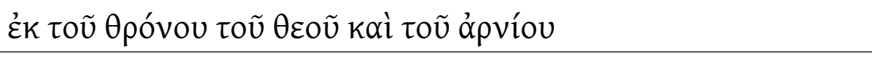 & Ap 22,1 \\
\hline 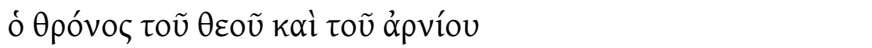 & Ap 22,3 \\
\hline
\end{tabular}

El hecho de que se repita la construcción casi siempre en genitivo o en dativo hace que la expresión resulte familiar a la asamblea que escucha el Apocalipsis y le resulta fácil percibir algunos detalles significativos:

a) En Ap 5,13; 7,9.10 la expresión aparece en un contexto claramente litúrgico. Los coros celestiales y las criaturas creadas rinden honor y gloria a Dios y al Cordero. Por lo que a través de la expresión formular se pone de manifiesto que el Cordero recibe el mismo culto de adoración de Dios. Además este hecho constituye una novedad dentro del corpus neotestamentario, pues en él las doxologías se refieren únicamente a Dios (Ga 1,5; Flp 4,20; 1 Pe 5,11) o a Jesús (Heb 13,21), pero no a ambos.

b) Cuando tiene lugar la apertura del sexto sello, el narrador comunica el terror que sienten los reyes y poderosos de la tierra no solo por Dios, sino también por el Cordero (Ap 6,16).

c) Finalmente el Cordero es considerado rey como lo es Dios (Ap 22,1.3). Con respecto a la cuestión de la realeza, resulta de interés el modo como Juan de Patmos aborda el tema. Según se refleja en el cuadro, a lo largo del relato el Cordero aparece junto a Dios, pero no compartiendo con Él su trono, pues de

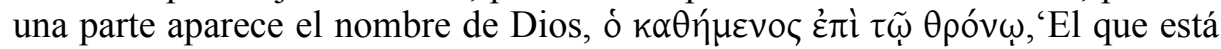
sentado en el trono', y de otra el Cordero. Sin embargo, cuando tiene lugar la

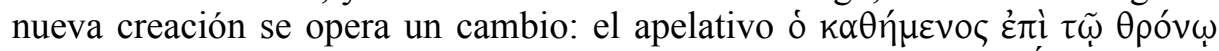
desaparece del Apocalipsis y el Cordero ya no aparece junto a Él, sino que comparte su trono (Ap 22,1.3), pues el vidente no menciona dos tronos, sino un único trono. Siguiendo a D. E. Aune, parece que se está refiriendo a un bisellium, es decir, a un trono con dos asientos ${ }^{67}$, cuya existencia nos es conocida gracias a los testimonios procedentes de la literatura (en Edipo en Colono de Sófocles,

\footnotetext{
${ }^{67}$ Aune (1998: 1177).
} 
se describe a Dike sentada con Zeus) y de la arqueología (en la Gema Augustea aparecen en un mismo trono Augusto y la Diosa Roma $)^{68}$. De este modo, Juan subraya que ambos poseen la misma autoridad y participan de la misma realeza.

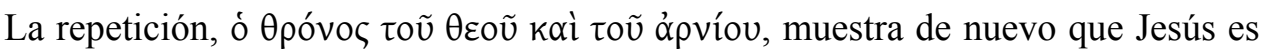
Dios, ya que solo si posee una naturaleza divina puede recibir el culto y la alabanza que Dios recibe (Ap 5,13; 7,9-10), puede ser temido como lo es Dios $($ Ap 6,16) y

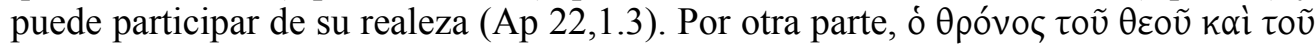
à $\rho v i ́ o u$ pone también de manifiesto de forma explícita que el Cordero es Dios, pero no se identifica con El que está sentado en el trono, pues en el relato son siempre dos personajes diferentes, de hecho Jesús nunca es designado como ó $\theta \varepsilon o ́ \varsigma$, sino únicamente

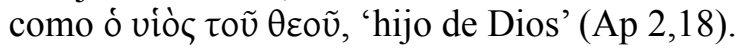

\subsection{Otros efectos acústicos}

Finalmente, en esta misma línea del estilo oral, podría mencionarse también el uso

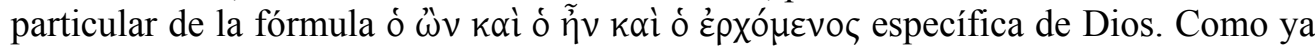
mencioné, aparece en un contexto litúrgico de revelación y de forma completa en el diálogo litúrgico inicial $($ Ap 1,4.8) y en la teofanía $(A p 4,8)$. A medida que avanza el relato, la fórmula reaparece manteniendo el contexto cultual, pero ó Épxó $\mu \varepsilon v o \zeta$ desaparece por completo, por lo que el oyente/lector escucha sencillamente: ó $\ddot{\omega} v$ kà ó $\tilde{\eta} v$ (Ap 11,17; 16,5). Se han aducido razones diversas que justifican la eliminación de

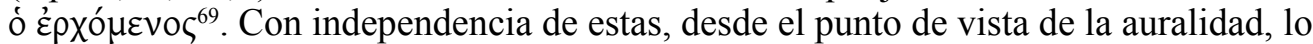
que el oyente/lector percibe en la escucha del relato es que tan pronto como desapa-

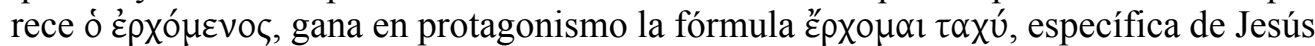
$(\text { Ap } 16,15 ; 22,7.12 .20)^{70}$. Además la fórmula reclama la escucha atenta del oyente/lector pues suele ir precedida habitualmente de la interjección idoú, 'imira!' (Ap 16,15; $22,7.12$ ), que sin duda alguna le interpela. Esta llamada de atención quizás es un modo de subrayar el mensaje que a través del efecto acústico se intenta transmitir, un mensaje que hoy se denominaría subliminal: Jesús, puesto que es Dios, como se ha insistido de distintos modos a lo largo de la obra, asume en su persona la venida de Dios. De manera que el Dios que se revela como ó é $\rho$ Xó $\mu \varepsilon v o \varsigma$ parece hacer efectiva su venida en el Apocalipsis a través de Jesús que de hecho está viniendo, dada la forma de presente

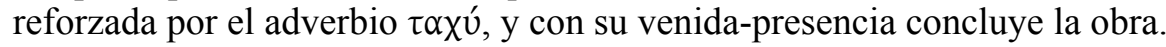

Tras el análisis realizado, queda claro que el oyente/lector del s. I d.C. era capaz de percibir que Juan de Patmos le transmitía en el Apocalipsis otro rostro de Dios que

${ }^{68}$ Aune (1997: 262). Como contraste, resulta significativo que en la representación del Apocalipsis de la serie de tapices de La Granja de San Ildefonso, encargados por Felipe II, concretamente en el octavo tapiz, El triunfo de la Iglesia, Dios-Padre aparece sentado en su trono y sobre sus rodillas el Cordero.

${ }^{69}$ Así Toribio Cuadrado (1993: 99.101) piensa que la omisión se debe al ejercicio activo de esa venida que ya se ha iniciado y sigue actuando. Boring (1986: 259) considera que la omisión obedece a que ya ha tenido lugar el eschaton en el relato.

${ }^{70} \mathrm{La}$ fórmula ya había sido empleada en la carta a la iglesia de Pérgamo (Ap 2,16) y de Filadelfia (Ap 3,11). 
rompía con los cánones de la tradición y suponía una novedad: el rostro de Dios que se revela en Jesucristo. Juan no elabora un discurso teológico, sino que se sirve de un arma bien sencilla: el estilo oral. Este le permite transmitir su doctrina de forma clara, pero de un modo sutil, constante y reiterativo. El estilo oral acaba desempeñando una función similar a lo que hoy se conoce como la psicología del anuncio que comunica claramente un mensaje al que se le añade otro $u$ otros de forma subliminal, apenas perceptibles para el público, pero que logra fijar la idea de fondo que se intenta transmitir. En este caso, la flexibilidad en el uso del lenguaje formular y las repeticiones insisten en que Dios es el que está sentado en el trono y Dios es Jesús, aunque en ellos no hay identidad de personas.

Quizás la razón que justifique la adopción de estos recursos haya que buscarla en el perfil de la comunidad a quien Juan de Patmos dirige su escrito. Probablemente estaría integrada por personas de diversa condición y de diferente nivel intelectual, recién convertidas del judaísmo y con una cierta formación helenística. Estas características facilitaban y, al mismo tiempo, obstaculizaban la asimilación del mensaje cristiano, ya que, de una parte, eran buenos conocedores de la Escritura, creían en la unicidad de Dios y, de otra, les podía resultar difícil reconocer la divinidad de Jesús y, aún admitiéndola, podía surgir la duda de si realmente Jesucristo, siendo hijo de Dios, era Dios. Era, pues, clave reforzar este principio y el estilo oral con sus propias estrategias de comunicación ofrece la herramienta didáctica para hacerlo.

\section{CONCLUSIÓN}

Tradición y novedad son el anverso y el reverso de la obra de Juan de Patmos de las que no puede prescindir el oyente/lector. Juan, heredero de una tradición secular, bebe de las fuentes de la Escritura para redactar su Apocalipsis. Por eso, el modo de presentar la teofanía, el modo con el que Dios se revela, el modo como le describe, incluso las propias palabras de Dios son típicamente veterotestamentarias. Hay, pues, un deseo expreso de mostrar la continuidad e identidad existente entre el Dios del final de los tiempos y el Dios de Israel. Sin embargo, desde el principio la obra se presenta

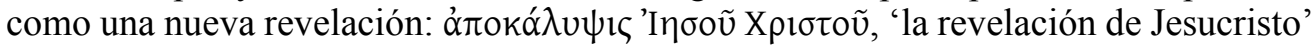
(Ap 1,1), y parte de esa nueva revelación consiste en mostrar la divinidad de Jesús que acaba por convertirse en una especie de sinfonía que envuelve el Apocalipsis. Tradición y novedad, pues, en el contenido, pero también tradición y novedad en el modo de transmitirlo.

A lo largo de este estudio se ha puesto de manifiesto que Juan de Patmos, como otros autores de su tiempo, adopta el estilo oral para facilitar al oyente/lector la lectura de su obra, pero también se sirve de él con otros fines. Las fórmulas de raigambre veterotestamentarias permiten que el oyente/lector rememore un pasado lejano en el tiempo, mientras se actualiza en el hoy del Apocalipsis, un buen ejemplo de ello lo

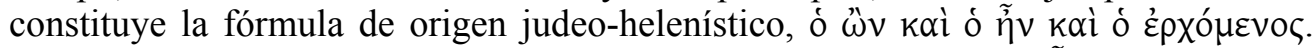

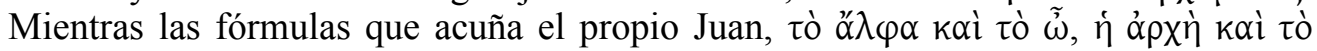

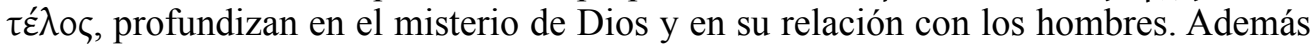
el uso anómalo e innovador del lenguaje formular, las repeticiones no solo permiten 
interpelar al oyente/lector, sino que desempeñan una cierta función didáctica y catequética: revelar el otro rostro de Dios, el rostro del Cordero de manera que quede claro y sin lugar a duda alguna la divinidad de Jesús.

El estilo oral pone de manifiesto que si bien el Apocalipsis es una obra escrita por un autor judío, buen conocedor de las Escrituras y fiel a su contenido, está dotada de una novedad que la aleja del judaísmo, pues presenta dos rostros de un único Dios: el del Padre y el del Cordero. Las estrategias propias del estilo oral permiten a Juan de Patmos comunicarlo de una forma sutil, apenas imperceptible, pero constante y repetitiva, que hacen de su texto apocalíptico una obra netamente cristiana. Aspecto que no puede ser obviado por el oyente/lector contemporáneo.

\section{BiBLIOGRAFÍA}

Aune, David E. (1987), «The Apocalypse of John and Greco-Roman Revelatory Magic», NTS 33: 490-491.

- (1997), Revelation 1-5, Dallas (Texas): Word Books.

- (1998), Revelation 17-22, Nashville (Tennessee): T. Nelson.

BDAG, BAUER, Walter (1979), A Greek-English Lexicon of the New Testament and Other Early Christian Literature, trad. y rev. ampliada de F.W. Gingrich - W. Danker, Chicago: University of Chicago Press.

Beale, Gregory K. (1999), The Book of Revelation. A Commentary on the Greek Text, Grand Rapids (Michigan) - Cambridge: The Paternoster Press - Carlisle.

Belano, Alessandro (2013), Apocalisse. Traduzione e analisi filológica, Roma: Aracne.

BorING, M. Eugene (1986), «The Lord Our God Almighty Reigns», Int 40: 257-269.

Brown, Raymond E. (1966), The Gospel According to John (I-XII), New York: Doubleday.

Charles, Robert H. (1920), A Critical and Exegetical Commentary on the Revelation of St. John. Introduction, Notes and Indices also the Greek Text and English Translation, vol. 1, Edinburgh: T \& T Clark.

CHester, Andrew (1986), Divine Revelation and Divine Titles in the Pentateuchal Targumim, Tübingen: Mohr.

Cicerón, Marco T., De l'invention (1994), ed. y trad. franc. de G. Achard, Paris: Les Belles Lettres.

Clément d'Alexandrie, Le pedagogue (1960), introd. y notas de H.-I. Marrou, trad. franc. de M. Harl, Paris: Editions du Cerf.

Clemente de Alejandría, Stromata IV-V (1998), introd., trad. y notas de M. Merino Rodríguez, Madrid: Ciudad Nueva.

Coluins, John J. (1992), «Sibylline Oracles», en D. N. Freedman, ed., The Anchor Bible Dictionary, vol. 6, New York: Doubleday: 3-4.

De Santiago Fernández, Javier (2004), «Materia y elementos iconográficos en las inscripciones cristianas de Mertola», Documenta \& Instrumenta 2: 193-226.

Dízz Macho, Alejandro (1984), Apócrifos del Antiguo Testamento, vol. IV, Madrid: Cristiandad. 
FERNÁNDEZ MARCos, Natalio (1998), Introducción a las versiones griegas de la Biblia, Madrid: CSIC.

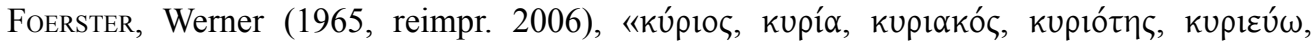

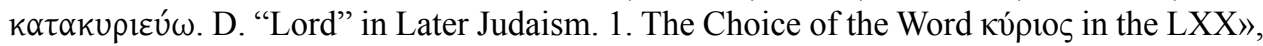
TDNT 3: 1081-1098.

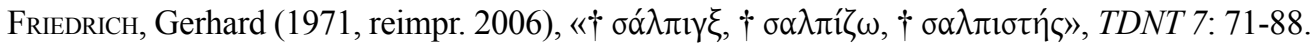
García Ureña, Lourdes (2013), El Apocalipsis: pautas literarias de lectura, Madrid: CSIC.

- (2014), «The Book of Revelation: a Written Text Towards the Oral Performance», en R. Scodel, Between Orality and Literacy: Communication and Adaptation in Antiquity, Leiden - Boston: Brill: 309-330.

Grelot, Pierre (1987), Los targumes. Textos escogidos, trad. esp. de A. Ortiz García, Estella: Verbo Divino.

Josephus, Jewish Antiquities (1943, reimpr. 1961), ed. y trad. ingl. de R. Marcus, vols. 6-7, London: William Heinemann.

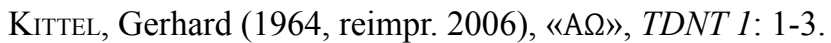

Louw, Johannes P., - NidA, Eugene A. (1988), Greek-English Lexicon of the New Testament Based on Semantic Domains, vols. 1-2, New York: United Bible Societies.

MAier, Johann, - SchäFER, Peter (1996), Diccionario del judaísmo, trad. esp. de D. Mínguez Fernández, Estella (Navarra): Verbo Divino.

Marguerat, Daniel - Bourquin, Yvan (2001), Per leggere i racconti biblici. La Bibbia si racconta. Iniziazione all'analisi narrativa, trad. it. de M. Zappella, Roma: Borla.

McNamara, Martin (1966), The New Testament and the Palestinian Targum to the Pentateuch, Rome: Pontifical Biblical Institute.

Migne, Jacques-P. (1841-1964), Patrologiae cursus completus. Series latina, vols. 1-221, Parisiis: Garnier Fratres et J.-P. Migne.

NBE, Nueva Biblia Española (1975), eds. Alonso SchöKel, Luis, - Mateos, Juan, Madrid: Cristiandad.

Norden, Eduard (1956), Agnostos theos. Untersuchungen zur Formengeschichte religiöser Rede, Stuttgart: Teubner.

Nuevo Testamento Trilingüe (1977, reimpr. 2005), eds. Bover, José M., - O’CALlaghan, José Madrid: BAC.

Nuevo Testamento $\left(2003^{2}\right)$, ed. IgLesias, Manuel, Madrid: Encuentro.

ONG, Walter J. (1982, reimpr. 1990), Orality and Literacy. The Technologizing of the Word, London - New York: Routledge.

Philon D'Alexandrie, De plantatione (1963), introd. trad. y notas de J. Pouilloux, Paris: Les Editions du Cerf.

Prigent, Pierre (2001), Commentary on the Apocalypse of St. John, trad. franc. de W. Pradels, Tübingen: Mohr Siebeck.

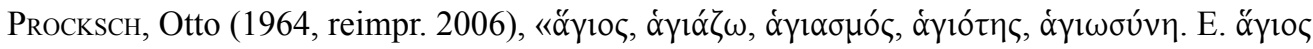
in the NT. The Holiness of God», TDNT 1: 88-97.100-115.

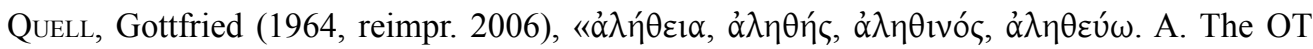
Term מֶֶֶ, TDNT 1: 232-237.

Real Academia Española (2009), Nueva gramática de la lengua española, vol. 2, Madrid: Espasa Libros. 
Robertson, Archibald T. (1934), A Grammar of the Greek New Testament in the Light of Historical Research, Nashville (Tennessee): Broadman Press.

Russo, Joseph A. (1992), «Oral Theory: Its Development in Homeric Studies and Applicability to Other Literatures», en M. E. Vogelzang - H. L. J. Vanstiphout, eds., Mesopotamian Epic Literature: Oral or Aural?, Lewiston (New York): Edwin Mellen Press, 7-21.

TDNT, KitTEL, Gerhard, - FriEDRICH, Gerhard (eds.) (1964-1976), The Theological Dictionary of the New Testament, vols. I-X, Grand Rapids (Michigan): Eerdmans.

Sagrada Biblia. Versión crítica sobre los textos hebreo, arameo y griego (1979²), eds. CANTERA Burgos, Francisco, e Iglesias GonzÁlez, Manuel, Madrid: EDICA.

Sagrada Biblia $\left(1978^{26}\right)$, eds. NÁCAR, Eloíno - ColungA, Alberto, Madrid: BAC.

Schnackenburg, Rudolf (1977), Il vangelo di Giovanni. Parte II, trad. it. de G. Cecchi, Brescia: Paideia Editrice.

SCHWEIZER, Eduard (1939), Ego eimi...: Die religionsgeschichtliche Herkunft und theologische Bedeutung der johanneischen Bildreden, zugleich ein Beitrag zur Quellenfrage des vierten Evangeliums, Göttingen: Vandenhoeck \& Ruprecht.

Sicre, José L. (1992), Profetismo en Israel. El Profeta. Los Profetas. El Mensaje, Estella: Verbo Divino.

Smalley, Stephen S. (2005), The Revelation to John. A Commentary on the Greek Text of the Apocalypse, London: SPCK.

Swete, Henry B. (1906, reimpr. 1999), The Apocalypse of St. John. The Greek Text with Introd., Notes and Indices, Eugene (Oregon): Wipf and Stock.

Thayer, Joseph H. $\left(1905^{4}\right)$, A Greek-English Lexicon of the New Testament. Being Grimm's Wilke's Clavis Novi Testamenti, Edinburgh: T \& T Clark.

Toribio Cuadrado, José F. (1993), «El viniente». Estudio exegético y teológico del verbo

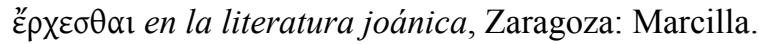

Trebolle, Julio (1993), La Biblia Judía y la Biblia Cristiana. Introducción a la Historia de la Biblia, Madrid: Trotta.

Vanni, Ugo (2005), Lectura del Apocalipsis. Hermenéutica, exégesis, teología, (1988), trad. esp. de H. Rey, Estella: Verbo Divino.

- (1976), «Un esempio di dialogo liturgico in Ap 1,4-8», Bib 57: 453-467.

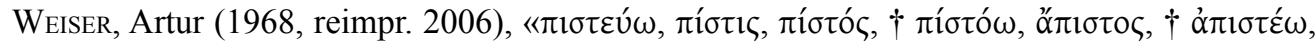

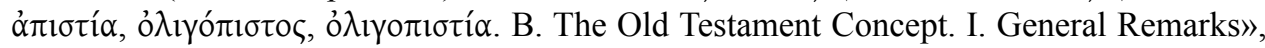
TDNT 6: 182-196. 